\title{
Clinical sequencing of soft tissue and bone sarcomas delineates diverse genomic landscapes and potential therapeutic targets
}

Benjamin A. Nacev ${ }^{1,2,3 \star}$, Francisco Sanchez-Vega ${ }^{4 \star}$, Shaleigh A. Smith ${ }^{4,5}$, Cristina R. Antonescu $^{6}$, Evan Rosenbaum ${ }^{1,2}$, Hongyu Shi ${ }^{7}$, Cerise Tang ${ }^{6,8}$, Nicholas D. Socci ${ }^{5,9}$, Satshil Rana ${ }^{6}$, Rodrigo Gularte-Mérida ${ }^{4}$, Ahmet Zehir ${ }^{6}$, Mrinal M. Gounder ${ }^{1,2}$, Timothy G. Bowler ${ }^{1}$, Anisha Luthra ${ }^{5,10}$, Bhumika Jadeja ${ }^{4}$, Azusa Okada ${ }^{4}$, Jonathan A. Strong ${ }^{4}$, Jake Stoller ${ }^{4}$, Jason E. Chan ${ }^{1}$, Ping Chi ${ }^{1,2,10}$, Sandra P. D’Angelo ${ }^{1,2}$, Mark A. Dickson ${ }^{1,2}$, Ciara M. Kelly ${ }^{1,2}$, Mary Louise Keohan ${ }^{1,2}$, Sujana Movva ${ }^{1,2}$, Katherine Thornton ${ }^{1,2}$, Paul A. Meyers ${ }^{11}$, Leonard H. Wexler ${ }^{11}$, Emily K. Slotkin ${ }^{11}$, Julia L. Glade Bender ${ }^{11}$, Neerav N. Shukla ${ }^{11}$, Martee L. Hensley ${ }^{1,2}$, John H. Healey ${ }^{4}$, Michael P. La Quaglia ${ }^{4,11,12}$, Kaled M. Alektiar ${ }^{13}$, Aimee M. Crago ${ }^{4,12}$, Sam S. Yoon ${ }^{4,12}$, Brian R. Untch ${ }^{4,12}$, Sarah Chiang ${ }^{6}$, Narasimhan P. Agaram ${ }^{6}$, Meera R. Hameed ${ }^{6}$, Michael F. Berger ${ }^{5,6,10}$, David B. Solit ${ }^{1,2,5}$, Nikolaus Schultz ${ }^{7,10}$, Marc Ladanyi ${ }^{6,10}$, Samuel Singer ${ }^{4,12 \ddagger}$, William D. Tap ${ }^{1,2 \ddagger}$

1. Department of Medicine, Memorial Sloan Kettering Cancer Center

2. Department of Medicine, Weill Cornell Medical College

3. The Laboratory of Chromatin Biology and Epigenetics, The Rockefeller University

4. Department of Surgery, Memorial Sloan Kettering Cancer Center

5. Marie-Josée and Henry R. Kravis Center for Molecular Oncology, Memorial Sloan Kettering Cancer Center

6. Department of Pathology, Memorial Sloan Kettering Cancer Center

7. Department of Epidemiology and Biostatistics, Memorial Sloan Kettering Cancer Center

8. Physiology, Biophysics and Systems Biology Graduate Program, Weill Cornell Medical College

9. Bioinformatics Core, Memorial Sloan Kettering Cancer Center

10. Human Oncology and Pathogenesis Program, Memorial Sloan Kettering Cancer Center 11. Department of Pediatrics, Memorial Sloan Kettering Cancer Center 
12. Department of Surgery, Weill Cornell Medical College

13. Department of Radiation Oncology, Memorial Sloan Kettering Cancer Center

* Equal contribution

‡ Co-corresponding authors

Running title: Genomic landscape of sarcomas

Keywords: mesenchymal neoplasm, targeted sequencing, sarcoma subtypes, genetic alteration, genetic variability

Financial support: This study was supported by the NCI MSK SPORE in Soft Tissue Sarcoma P50 CA217694, the Marie-Josée and Henry R. Kravis Center for Molecular Oncology, and Cycle for Survival. B.A.N. was funded by the National Cancer Institute (K08 CA245212). The Memorial Sloan Kettering Cancer Center Support Grant (P30 CA008748) supported core facility resources used in this research. P.C. is supported by the National Institute of Health/National Cancer Institute (R01 CA228216), Orphan Products Grants Program/U.S. Food and Drug Administration (R01 FD005731), Cycle for Survival, and the Geoffrey Beene Cancer Research Fund.

\section{Corresponding authors:}

William D. Tap, MD

1275 York Ave.

New York, NY 10065

646-888-4163

tapw@mskcc.org
Samuel Singer, MD 1275 York Ave. New York, NY 10065 212-639-2164 singers@mskcc.org

Number of figures and tables: 7 main figures, 4 supplementary figures, 5 supplementary tables 


\section{Abstract}

2 The genetic, biologic, and clinical heterogeneity of sarcomas poses a challenge for the

3 identification of therapeutic targets, clinical research, and advancing patient care. Because there

4 are > 100 sarcoma subtypes, in-depth genetic studies have focused on one or a few subtypes.

5 Herein, we report a comparative genetic analyses analysis of 2,138 sarcomas representing 45

6 pathological entities. This cohort was prospectively analyzed using targeted sequencing to

7 characterize subtype-specific somatic alterations in targetable pathways, rates of whole genome

8 doubling, mutational signatures, and subtype-agnostic genomic clusters. The most common

9 alterations were in cell cycle control and TP53, receptor tyrosine kinases/PI3K/RAS, and

10 epigenetic regulators. Subtype-specific associations included TERT amplification in intimal

11 sarcoma and SWI/SNF alterations in uterine adenosarcoma. Tumor mutational burden, while

12 low compared to other cancers, varied between and within subtypes. This resource will improve

13 sarcoma models, motivate studies of subtype-specific alterations, and inform investigations of

14 genetic factors and their correlations with treatment response. 
medRxiv preprint doi: https://doi.org/10.1101/2021.10.28.21265587; this version posted October 30, 2021. The copyright holder for this preprint (which was not certified by peer review) is the author/funder, who has granted medRxiv a license to display the preprint in perpetuity.

It is made available under a CC-BY-NC-ND 4.0 International license .

\section{Introduction}

16 Sarcomas are mesenchymal malignancies of the bone or soft tissue that arise in diverse organ

17 sites and display a range of clinical behavior from indolent to aggressive. Sarcomas are also

18 rare tumors, representing $<1 \%$ of all malignancies in adults (1). Although the diagnosis and

19 management of sarcomas has slowly improved over the last decade, about $40 \%$ of patients with

20 newly diagnosed sarcoma eventually die of disease. One barrier to improving outcomes in

21 sarcoma patients is the cancer's genomic and biologic complexity, with more than 100 different

22 subtypes now recognized by the World Health Organization (2).

23 Advances in clinical tumor genomic analyses have improved tumor classification; sarcomas are

24 now classified into two broad genetic groups (3). Sarcomas often have either simple karyotypes,

25 harboring genetic translocations or activating mutations, or highly complex karyotypes, including

26 numerous genomic rearrangements and large chromosomal gains and losses, commonly

27 involving cell cycle genes such as TP53, MDM2, RB1, and CDK4. Toward identifying

28 therapeutic targets and designing precision oncology trials based on specific sarcomas' genetic

29 features, a comprehensive study of soft tissue sarcomas was performed by The Cancer

30 Genome Atlas network, which analyzed 206 samples within 7 common subtypes; rarer ones

31 were represented by as few as 5 cases (4). Analysis of a larger cohort could define the

32 frequency of potentially actionable alterations in rare sarcoma subtypes and broadly compare

33 the frequency of genetic alterations across subtypes to facilitate better diagnostic precision,

34 identify prognostic biomarkers, improve laboratory-based modeling of sarcomas, and generate

35 novel hypotheses on underlying disease mechanisms.

36 Here, we leveraged an institution-wide tumor genomic profiling initiative to prospectively analyze

372,138 sarcomas encompassing 45 subtypes to identify subtype-specific somatic mutations and

38 copy number alterations and characterize tumor mutation burden (TMB) and microsatellite 
medRxiv preprint doi: https://doi.org/10.1101/2021.10.28.21265587; this version posted October 30, 2021. The copyright holder for this preprint (which was not certified by peer review) is the author/funder, who has granted medRxiv a license to display the preprint in perpetuity.

It is made available under a CC-BY-NC-ND 4.0 International license .

39 instability. Paired tumor and normal DNA samples were analyzed using the FDA-cleared

40 Memorial Sloan Kettering-Integrated Mutation Profiling of Actionable Cancer Targets (MSK-

41 IMPACT) next generation sequencing platform (5).

\section{Results}

\section{Study population characteristics}

45 A total of 2,138 bone and soft tissue sarcoma samples were analyzed. Median patient age was

4654 years (range $<1->90$ years); 1,098 (51.4\%) were female. Most were primary tumors; 790

47 samples (36.9\%) were metastases (Supplementary Table 1). The analyzed dataset included

4845 distinct pathologic entities as assessed by expert sarcoma pathologists. Twenty-two

49 subtypes were represented by $\geq 20$ tumor samples and were therefore used as our core

50 subtype set for analyses (Fig. 1A). Data from less represented subtypes (Fig. 1B) are included

51 in this cohort as a resource. The most common subtypes were gastrointestinal stromal tumor

52 (GIST; $n=395,18.5 \%$ ), dedifferentiated liposarcoma (DDLS; $\mathrm{n}=167,5.4 \%$ ), uterine

53 leiomyosarcoma (ULMS; $n=165,5.3 \%$ ), and undifferentiated pleomorphic sarcoma (UPS; $n=$

54 145, 4.6\%) (Fig. 1B). Rare subtypes within the core set include angiosarcoma (ANGS; $n=101$,

$553.2 \%$ ), desmoplastic small round cell tumor (DSRCT; $n=53,1.7 \%$ ), and perivascular epithelioid

56 cell neoplasms (PECOMA; $n=30,0.96 \%$ ) (Fig. 1B). As expected, the age distribution varied

57 among subtypes, as did tumor location (Fig. 1A, Supplementary Table 1). Among the more

58 common subtypes, myxofibrosarcoma (MFS) had the oldest median age (68 years), whereas

59 embryonal rhabdomyosarcoma (ERMS) had the youngest (8 years). Similarly, sex distribution

60 was not uniform among subtypes (Fig. 1A); PECOMA was more common in females (23/30;

$6176.6 \%$ ) and DSRCT more common in males (48/53; 90.5\%), as was DDLS (males 115/164;

$6268.8 \%$ ) (Fig. 1A). Among the most common subtypes, survival rate differences were most 
medRxiv preprint doi: https://doi.org/10.1101/2021.10.28.21265587; this version posted October 30, 2021. The copyright holder for this preprint (which was not certified by peer review) is the author/funder, who has granted medRxiv a license to display the preprint in perpetuity.

It is made available under a CC-BY-NC-ND 4.0 International license .

63 apparent starting at 3 years post-sequencing. Myxoid/round cell liposarcoma (MRLS) and GIST

64 patients had the highest 3-year survival rates (both > 75\%), whereas ANGS and alveolar

65 rhabdomyosarcoma (ARMS) patients had the lowest (34\% and 19\%, respectively) (Fig. 1C).

66 Subtype-specific mutation analysis

67 Given the heterogeneity in sarcoma subtypes, their biologic behavior, and clinical presentation,

68 we sought to define the genetics of individual subtypes at both the gene (mutation, gene fusion,

69 and copy number alteration) and functional pathway levels. MSK-IMPACT identified at least one

70 driver mutation in the majority of subtypes (Fig. 2A, Supplementary Table 2). Overall, TMB

71 among sarcomas was low, whereas the fraction genome altered (FGA) in most cases was

72 relatively high compared with other cancers, consistent with prior reports (Fig. 2A) (4). Both

73 varied greatly among sarcoma subtypes, especially FGA. We performed MutSig and MuSiC

74 analyses to identify significantly recurrently mutated genes in each subtype (Fig. 2B). As

75 expected, TP53 and RB1 were significantly altered across multiple subtypes, but at markedly

76 different frequencies. Within GIST, we identified several frequently mutated genes in addition to

77 previously known drivers such as KIT, SDHA, and PDGFRA (6). These included the histone

78 methyltransferase SETD2 (4\%), the MYC binding partner and transcription factor MAX (4\%),

79 and MGA (3\%), which binds the MAX-MYC complex (7).

80 Additional subtypes with recurrently mutated genes of potential biologic or clinical relevance

81 included ANGS ( $\mathrm{n}=101$ ), in which we identified recurrent mutations in receptor tyrosine kinases

82 involved in angiogenesis including KDR (VEGFR2; 19\%) and FLT4 (VEGFR3; 9\%) as well as

83 another receptor tyrosine kinase, EPHA5 (9\% of cases). The mutations in EPHA5 and FLT4

84 were all variants of unknown significance (VUS). The VUS in FLT4 all affect the kinase domain

85 or the C-terminus, implying a possible functional consequence (Fig. 2C). In Ewing sarcoma (ES;

$86 \mathrm{n}=99), 10 \%$ of samples carried mutations in the cohesion complex component STAG2,

87 confirming prior reports (8). In ULMS, MED12, a member of the transcription elongation 
complex, was altered in $16 \%$ of cases, most frequently missense mutations at glycine 44 , as

89 reported previously (Fig. 2B) (9).

90 In PECOMA, SFT, LMS, ULMS, and ES, driver mutations were represented in a cancer cell

91 fraction (CCF) of close to 1.0, suggesting that these represent a large clonal population (Fig.

92 2D). The CCF for VUS was overall similar to that of drivers within most subtypes, with the

93 exception of MFS, OS, and UPS, which suggests that in some cases these VUS could have an

94 unrecognized function, calling for further studies to determine their roles in oncogenesis and

95 progression.

Copy Number Alterations by Subtype

97 As many sarcomas are driven by copy number alterations, we analyzed these changes across

98 the whole cohort, including in subtypes not classically thought to be driven by them (Fig. 3). For

99 instance, in GIST patients (evaluable $n=371$ ), there were frequent copy number loss events

100 involving chromosomes 1, 14, 15, and 22 (Fig. 3A). Translocation-driven sarcomas, e.g. ES,

101 DSRCT, and SYNS, exhibited highly recurrent copy number changes, indicating that there may

102 be additional relevant genetic events beyond the driver translocations (Fig. 3B). We identified a

103 diversity of chromosome arms (e.g. 5p, 8q, and 10p) that were recurrently affected by copy

104 number variation across multiple common subtypes (Fig. 3B). Of note, 12q amplifications in

105 DDLS and WDLS patients were not wide enough to be called in arm-level analysis (Fig. 3B,

106 left), though they were clearly observed as a strong focal event in copy number profiles (Fig.

107 3A, B, right). In most cases, these arm-level copy number events were not linked to a specific

108 gene. However, there were some exceptions including significant gains of MYC on chromosome

$1098 \mathrm{q} 24$ in OS, EPIS, ERMS, and ANGS, as well as significant gain of a negative regulator of NF-

110 kB signaling, TNFAIP3, in DDLS (Fig. 3B). As expected, we observed more widespread copy 
111 number changes in classically copy number-driven subtypes such as LMS, ULMS, MFS, and

112 OS compared with the rest of the cohort.

113 Despite sharing CDK4 and MDM2 amplification events, DDLS is more aggressive than WDLS

114 and has increased risk for distant spread (10). Therefore, we compared rates of amplifications

115 between WDLS and DDLS, and found greater rates of amplification of the oncogenes GLI1

116 (8.5\% vs. $25.3 \%)$, TERT (6.3\% vs. $14.4 \%)$, and JUN (0\% vs. $13.8 \%)$ in DDLS. The Jun

117 transcription factor positively regulates the expression of cyclin D1, a CDK4/6 cyclin partner,

118 and amplification of JUN in DDLS is associated with a more aggressive phenotype (4), calling

119 for investigation of whether CDK4 and JUN co-amplification drives progression to DDLS or

120 modulates response to CDK4 inhibition. Amplification of the GLI1 transcription factor,

121 downstream of Sonic Hedgehog (Shh) signaling, has previously been reported (11); this

122 confirmation furthers rationale for studying Shh pathway inhibition in DDLS. GL/1 amplification

123 and JUN amplification were mutually exclusive.

124 OS, UPS, ERMS, and MPNST had high frequencies of WGD, all around 50\%, ranking among

125 the highest even among a wide variety of cancers for which WGD was previously analyzed (Fig.

126 3C; Supplementary Fig. S1A) (12). In keeping with the notion that MFS is on a genetic

127 continuum with UPS (4), UPS and MFS had similar WGD frequencies. Despite being copy

128 number variation (CNV)-driven, WDLS and DDLS had lower rates of WGD frequency, as did

129 many translocation-driven subtypes including SYNS, ES, DSRCT, and MRLS. In sarcomas,

130 WGD was associated with worse overall survival among metastatic $(p=0.042)$ but not primary

131 cases ( $p=0.391$; Supplementary Fig. S1B). Among specific subtypes, WGD was associated

132 with worse overall survival (from time of sequencing) in metastatic UPS ( $p=0.022$; Fig. 3D), but

133 not MFS ( $p=0.78$; Supplementary Fig. S1C).

134 Commonly Disrupted Pathways in Sarcoma 
135 Pathway-specific analyses within each sarcoma subtype for which $\geq 20$ samples were available

136 (Fig. 4A, genes in each pathway listed in Supplementary Table 3) revealed that a number of 137 pathways important in carcinomas were infrequently altered in sarcoma, including TGF $\beta$, WNT, 138 Hippo, Notch, and NRF2 (Fig. 4A, right panel). By contrast, the cell cycle and TP53 pathways 139 were altered in at least half of samples in 8 of the 22 most common subtypes. For instance, 140 DDLS and WDLS demonstrated cell cycle or TP53 pathway alterations in 214/215 (99\%) of 141 samples, most commonly through co-amplification of CDK4 and the E3 ubiquitin ligase that 142 targets p53 for degradation, MDM2 (Fig. 4A) (13,14). Many of the sarcomas with infrequent 143 alterations $(<10 \%)$ in the cell cycle and TP53 pathways were driven by translocations (e.g. 144 MRLS, DSRCT, SYNS) or alteration in the SWI/SNF remodeling complex (epithelioid sarcoma 145 [EPIS]) (Fig. 4A), highlighting a distinct mechanism of pathogenesis. An exception was solitary 146 fibrous tumor (SFT), which is driven by the NAB2-STAT6 fusion oncogene, and has oncogenic 147 TP53 alteration in $28 \%$ of cases (Fig. 4A) (15).

148 The PI3K pathway was frequently altered in some of the most prevalent subtypes in our dataset 149 including MRLS (41\%), PECOMA (40\%), ULMS (30\%), pleomorphic liposarcoma (PLLS; 22\%), 150 UPS (20\%), and soft tissue leiomyosarcoma (LMS; 20\%) (Fig. 4A, right panel). Among these 151 subtypes, PTEN and PIK3CA were the most frequently affected genes except in PECOMA 152 where TSC2 loss of function alterations were most common (30\%) (Fig. 4A, 4B). PTEN loss of 153 function alterations predominate in LMS and ULMS (14\% and $21 \%$, respectively), whereas in 154 MRLS, PIK3CA mutations were most frequent, occurring in $25 \%$ of cases, consistent with our 155 prior findings (16). In MRLS, PTEN loss is observed in $21 \%$ of cases, some of which were 156 concurrent with PIK3CA mutations (4 PIK3CA mutations in 10 PTEN loss cases). In contrast, in 157 UPS, PTEN alterations were identified in $8 \%$ of samples and PIK3CA in $3 \%$; only 1 of the 11 158 cases with a PTEN alteration had a concurrent PIKC3A mutation. Notably, PTEN loss of 
medRxiv preprint doi: https://doi.org/10.1101/2021.10.28.21265587; this version posted October 30, 2021. The copyright holder for this preprint (which was not certified by peer review) is the author/funder, who has granted medRxiv a license to display the preprint in perpetuity.

It is made available under a CC-BY-NC-ND 4.0 International license .

159 function has also been proposed as a predictor of non-response to immune checkpoint inhibition

160 in ULMS (17).

161 Because a pan-cancer MSK-IMPACT analysis identified TERT promoter mutations in a subset

162 of sarcomas (18), we investigated their frequency as a function of sarcoma subtype (Fig. 4C).

163 We identified oncogenic TERT amplifications in 44\% (8/18) of intimal sarcoma (INTS) and TERT

164 promoter mutations in $79 \%(38 / 48)$ of MRLS, $46 \%(24 / 52)$ of SFT, and $35 \%(5 / 14)$ of

165 dedifferentiated chondrosarcoma (DDCHS). In DDLS, oncogenic TERT promoter alterations

166 were present in $16 \%$ of samples (27/167) and were almost entirely amplifications $(n=24)$.

167 TERT copy number alterations have not yet been described in INTS, perhaps due to the low

168 incidence of this rare subtype. The TERT locus is distinct from that of the MDM2 and CDK4

169 amplifications (19) that are hallmarks of INTS, implicating TERT amplification as a potential

170 independent contributor to pathogenesis.

171 Alterations in DNA damage repair (DDR) pathway genes have been associated with

172 development of sarcomas (20), and are of particular clinical interest as PARP inhibition has

173 activity in select carcinomas with homologous recombination deficiency and immune checkpoint

174 blockade has activity in certain tumors with microsatellite instability $(21,22)$. Our analysis of

175 DDR pathway alterations found that $9.6 \%$ of all samples harbored an oncogenic somatic

176 alteration in a DDR pathway. Among subtypes with more than 20 samples, the frequency of

177 DDR gene alterations was highest in ULMS (24\%), MPNST (16\%), PLLS (13\%), PECOMA

178 (13\%), ANGS (13\%), LMS (10\%), and OS (10\%) (Fig. 4A, right panel). The most frequently

179 altered genes across subtypes were BRCA2 (1.4\% of all samples), RAD51B (1.1\%), CHEK2

180 (1.0\%) ATM (0.9\%), FANCA (0.6\%), and RAD51 (0.6\%). Consistent with a previous report in

181 uterine sarcomas (23), nearly half of $B R C A 2(41 \%)$ and $R A D 51 B(47 \%)$ alterations occurred in

182 sarcomas of uterine origin, with $R A D 51 B$ or BRCA2 each mutated in $7 \%$ of ULMS cases.

183 Similarly, $35 \%$ of the 14 uterine adenosarcomas also had an altered DDR gene, all deep 
medRxiv preprint doi: https://doi.org/10.1101/2021.10.28.21265587; this version posted October 30, 2021. The copyright holder for this preprint (which was not certified by peer review) is the author/funder, who has granted medRxiv a license to display the preprint in perpetuity.

It is made available under a CC-BY-NC-ND 4.0 International license .

184

185

186

187

188

189

190

191

192

193

194

195

196

197

198

199

200

201

202

203

204

205

206

207

208

deletions. Five percent of ANGS had oncogenic mutations and another $5 \%$ had a VUS in ATM. Given the association of ANGS with prior ionizing radiation, ATM mutations may represent a convergent pathogenic mechanism for accumulation of DNA damage. Of the 15 sarcomas $(0.7 \%)$ with an altered mismatch repair (MMR) gene (MLH1, MSH2, MSH6, or PMS2), one (LMS) was microsatellite instability (MSI)-high by MSISensor and had a high TMB.

Epigenetic dysregulation contributes to the pathogenesis of several sarcoma subtypes (24). In SYNS, EPIS, malignant rhabdoid tumors, and MPNST, this occurs through alterations of chromatin-remodeling and -modifying complexes; in chondroblastoma, CHS, UPS, giant cell tumors of bone, and osteosarcoma through oncogenic histone mutations. In light of emerging pharmacologic strategies to study and therapeutically target epigenetic regulatory proteins, we identified sarcoma subtypes characterized by epigenetic pathway alterations (Fig. 4A; Supplementary Table 3) (25). As expected, 75\% of EPIS had loss-of-function deletions, truncating mutations, or intragenic fusions in $S M A R C B 1$. In addition, the epigenetic pathway was one of the most altered pathways among the highly prevalent subtypes in our dataset. Pathogenic alterations in epigenetic pathway genes (Supplementary Table 3) were observed in $64 \%$ of MPNST, $49 \%$ of ULMS, $45 \%$ of PLLS, $43 \%$ of CHS, $42 \%$ of UPS, $36 \%$ of MFS, and $32 \%$ of OS (Fig. 4A). By contrast, these alterations were infrequently observed $(<10 \%)$ in WDLS, ARMS, and MRLS, suggesting subtype specificity.

We determined the association with specific subtypes of epigenetic pathway genes contributing to a specific biochemical function (e.g. DNA methylation, chromatin remodeling) and complex (e.g. PRC1, PRC2, MLL3/4) (Fig. 4D; Supplementary Fig. 2; Supplementary Table 4). Genes involved in histone modification were altered in $48 \%$ of MPNST, $42 \%$ of sclerosing epithelioid fibrosarcoma (SEF), 36\% of uterine adenosarcoma (UAS), and 36\% of high-grade endometrial stromal sarcoma (HGESS). ERMS had frequent alterations in in the transcriptional co-repressor and non-canonical PRC1 complex member BCOR (19\% total, 16\% oncogenic), which were 
mutually exclusive with DICER1 alterations (12\% oncogenic). Both alterations were more

210 prevalent in our population than in prior studies $(26,27)$.

211 Genes involved in chromatin remodeling were altered at similarly high frequencies: $76 \%$ of 212 epithelial sarcoma (EPIS), $39 \%$ of ULMS, $26 \%$ of UPS, $24 \%$ of MFS, and $18 \%$ of MPNST. In a 213 significant portion of these cases, the histone chaperone ATRX drove these high rates 214 (Supplementary Fig. 2). We also note the unexpected finding that UAS $(\mathrm{n}=14)$, a rare 215 sarcoma subtype, had oncogenic alterations in genes encoding subunits of the SWI/SNF 216 chromatin remodeling complex in $43 \%$ of patients, with $A R I D 1 A$ and PBRM1 most frequently 217 affected (Fig. 4D, Supplementary Fig. 2). Interestingly, UAS also had alterations in histone218 modifying genes in $36 \%$ of cases.

219 As epigenetic alterations are more frequent in DDLS (25\%) than WDLS (8\%) and we have 220 previously found epigenetic dysregulation to contribute to DDLS (28), we further examined 221 differences between DDLS and WDLS. Histone-modifying and histone chaperone/chromatin222 remodeling alterations occur in $15 \%$ and $13 \%$ of DDLS cases, respectively, compared with $4 \%$ 223 each of WDLS (Fig. 4D). This suggests that loss of epigenetic regulation could be an important 224 contributor to dedifferentiation.

225 We also examined epigenetic pathways without filtering for alterations already established as oncogenic, which is a strategy we recently employed to generate hypotheses in an analysis of 227 genetic alterations in OS (Supplementary Fig. 3) (29). This analysis identified the histone 228 methyltransferase $K M T 2 D / M L L 4$ as more frequently altered in MFS (16\%) compared with other 229 subtypes including the closely related UPS (6\%) (4). Histone-modifying enzymes were altered in $23020 \%$ of SYNS, among which KMT2B and SETD2 were altered in $6 \%$ and $7 \%$ of samples, 231 respectively. We also found that the transcriptional corepressor NCOR1, which complexes with 232 HDAC3 and other deacetylases to regulate the activity of transcription factors such as the 
233 retinoic acid receptor and thyroid hormone receptor (30), was altered in 10\% of ULMS, $19 \%$ of

234 LMS, and $21 \%$ of OS, mostly through amplification. NCOR1 has also been shown to regulate

235 transcription factors important in mesenchymal lineages including the MEF2 family and PPAR

236 which regulate myo- and adipogenesis, respectively (31). Several other genes within the same

237 cytoband as NCOR1, 17p12-p11.2, were co-amplified, including FLCN, MAP2K4, AURKB, and

238 ALOX12B (Supplementary Fig. 4A). Amplifications of MYOCD, whose genomic location is

239 within a region previously found to be amplified in LMS (32), were not detected because this

240 gene is not represented on the MSK-IMPACT panel. Except for $A L O X 12 B$, the 17p copy

241 number gains of MSK-IMPACT-assessed genes were associated with increased gene

242 expression in the sarcoma TCGA analysis (Supplementary Fig. 4B). Thus, one or more of

243 these genes could play a pathogenic role.

244 Mutual Exclusivity and Co-occurrence

245 To better understand how gene- and pathway-level alterations interact, we analyzed their co-

246 occurrence and mutual exclusivity (Fig. 5A). As expected, KIT and PDGFRA alterations were

247 mutually exclusive in GIST and CDK4 and MDM2 co-occurred in DDLS. In OS, KDR alterations

248 co-occurred with KIT and PDGFRA, as did the latter two with each other, suggesting

249 dysregulation of signaling through these 3 RTK genes located at the $4 q 12$ locus (29). TP53

250 alterations were mutually exclusive with $C D K N 2 A / B$ in GIST and ULMS, but not in UPS. In SFT

251 and ES, TP53 alterations co-occurred with STAG2 and TERT alterations, respectively,

252 suggesting context dependence for alterations co-occurring with TP53. In UPS, ATRX and NF1

253 alterations, which are mostly loss-of-function events, were mutually exclusive, suggesting

254 biologically different subgroups.

255 At the pathway level, cell cycle and DDR pathway alterations significantly co-occurred (false

256 discovery rate $[\mathrm{FDR}]<0.05)$ with those in other pathways. For instance, cell cycle alterations 
medRxiv preprint doi: https://doi.org/10.1101/2021.10.28.21265587; this version posted October 30, 2021. The copyright holder for this preprint (which was not certified by peer review) is the author/funder, who has granted medRxiv a license to display the preprint in perpetuity.

It is made available under a CC-BY-NC-ND 4.0 International license .

257 co-occurred with MYC pathway alterations in GIST, with PI3K pathway alterations in GIST and

258 ULMS, and with RTK/RAS alterations in GIST, OS, and SYNS (Fig. 5A). DDR pathway

259 alterations co-occurred with MYC pathway alterations in ULMS and MRLS, epigenetic pathway

260 alterations in GIST and DDLS, Hippo pathway alterations in DDLS, and cell cycle alterations in

261 ES. There were no examples of significant mutual exclusivity at the pathway level.

$262 \quad$ ATRX Alterations across Subtypes

263 ATRX stood out across subtypes as frequently affected by loss-of-function events (Fig. 5B); this

264 gene was altered in $\geq 10 \%$ of cases in 7 subtypes: ULMS, PLLS, UPS, MFS, PECOMA, LMS,

265 and ANGS. In ULMS, which had the highest rate of ATRX alterations, the frequency was

266 roughly 1 in 3 cases. That $A T R X$ loss-of-function events occur in both copy number- and

267 translocation-driven subtypes, although at lower frequency in the latter, raises the possibility that

268 they may serve a fundamental role in the biology of a molecular subset of these subtypes.

269 ATRX loss-of-function mutations were more frequent than deletion events, independent of

270 subtype, despite the overall low mutation rate. Our analysis also captured intra- and intergenic

$271 \quad$ ATRX fusion events.

272 Unsupervised Clustering of Subtypes

273 To assess genetic similarities among subtypes, we grouped samples on the basis of genetic

274 alterations by unsupervised clustering (Fig. 5C), which generated 15 distinct clusters

275 subsequently named according to their prevailing subtype and/or genetic feature. Some

276 subtypes and clusters were closely associated (Fig. 5D). These included EPIS and the

277 SMARCB1 cluster, DSRCT and WT1, and WDLS and DDLS with MDM2-CDK4. These

278 groupings largely reflect known or presumed drivers in these subtypes and reinforces their

279 central roles therein. 
medRxiv preprint doi: https://doi.org/10.1101/2021.10.28.21265587; this version posted October 30, 2021. The copyright holder for this preprint (which was not certified by peer review) is the author/funder, who has granted medRxiv a license to display the preprint in perpetuity.

It is made available under a CC-BY-NC-ND 4.0 International license.

280 Other clusters were heterogeneous and comprised of many subtypes. One such cluster was

281 associated with frequent alterations in TERT, which dominated by MRLS and SFT, but also

282 included small populations of other sarcoma subtypes. Another cluster lacked any

283 predominantly altered gene. This 'other' cluster included the majority of samples in some

284 histotypes (e.g. ANGS and CHS) but also included samples from multiple subtypes that are

285 represented more commonly in other clusters (e.g. LMS and UPS), suggesting that they may be

286 genetic outliers among those subtypes.

287 Notably, alterations in TP53, thought of as a canonical driver in many sarcomas, were

288 associated with 4 closely related clusters, each with a distinct association with co-occurring

$289 A T R X$ and/or $R B 1$ alterations. In contrast, the RB1-altered/TP53-WT ("RB1") group clustered

290 distantly from the TP53-altered groups and was more closely related with $C D K N 2 A / B$ and 'other'

291 groups. ULMS, PLLS, and UPS were represented in both the TP53-altered groups and the RB1-

292 altered/TP53-WT group.

293 For each subtype we also assigned an entropy score with respect to the clustering assignments

294 (Fig. 5D). WDLS, DDLS, and DSRCT had the lowest entropy, suggesting relatively uniform

295 genomic profiles within each subtype, whereas ULMS, UPS, and OS had high entropy,

296 suggesting that these pathologically defined entities harbor multiple distinct genetic variants.

297 Tumor Mutational Burden, Microsatellite Instability, and Mutational Signatures

298 Two recent immune checkpoint blockade trials in sarcoma demonstrated low overall response 299 rates, though rates varied among subtypes $(33,34)$. Thus, predictive biomarkers for response to 300 checkpoint blockade are needed to deconvolute this heterogeneity and aid in the design of 301 future clinical trials. As microsatellite instability predicts response to pembrolizumab (21), and 302 tumors with high TMB are more likely to respond to immune checkpoint blockade (35), we 303 determined MSI status and TMB for each subtype (Fig. 6A and 6B, Supplementary Table 1). 
304 While the median TMB for sarcomas was low compared to many carcinomas (4), there is 305 considerable heterogeneity within and between the more common subtypes in our cohort (inter306 subtype median range 0.9-3.0) (Fig. 6A). The median TMB was greatest in ANGS (3.0), UPS 307 (2.6), and ULMS (2.6) and lowest in WDLS (0.9), EPIS (0.9), and RCS (other) (0.9). However, in 308 certain subtypes, the distribution of TMB had a long upper tail and was skewed towards higher 309 TMB (Fig. 6A). TMB was $\geq 5$ mut/Mb in $25 \%$ of ANGS, $15 \%$ of ULMS and UPS, and $13 \%$ of 310 ERMS. Only two subtypes had $\geq 5 \%$ of samples with a TMB of $\geq 10$ mut/Mb: ANGS (7.6\%) and 311 UPS (6.7\%).

312 Only 5 of 1893 samples evaluable for MSI status were MSI-high (by MSIsensor score $\geq 10$ ), 313 including one UPS, one LMS, and 3 ULMS (Fig. 6B). Of these, 4 were confirmed to be MSI-high 314 by a conventional PCR-based MSI assay. MSIsensor scores varied widely between subtypes

315 (Supplementary Table 1). Overall, while microsatellite instability corresponded with high TMB, 316 the inverse was not true.

317 To understand mechanisms contributing to extensive genetic alterations, we examined 318 mutational signatures in samples with $\geq 15$ single nucleotide variants (SNVs) (Fig. 6C). A UV 319 mutational signature was observed in a subset of ANGS and was most strongly observed in 320 samples at the highest end of the TMB spectrum within that group. Of these 16 samples, 11 had 321 a head and neck primary site. Interestingly, a subset of UPS also harbored a UV signature and 322 a higher TMB, while another subset of highly mutated UPS was dominated by an aging 323 signature, suggesting alternative mechanisms for high TMB within UPS.

324 Subtype-specific actionable alterations

325 Toward improved detection of targetable alterations for each subtype and patient, we analyzed 326 genetic alterations by actionability according to OncoKB (Fig. 7) (36). As expected, level 1 327 alterations, defined as FDA-recognized biomarkers for response to an FDA-approved drug, 

deletion was noted in $66 \%$ of EPIS. Level 2 alterations, defined as guideline-supported

330 standard-of-care biomarkers for an FDA-approved drug, were seen in $>90 \%$ of WDLS and 331 DDLS related to CDK4 amplification. In the same subtypes, MDM2 amplifications in > 90\% of

332 cases were deemed Level 3A, for which compelling evidence supports use as a predictive 333 biomarker for an existing drug. Many other observed alterations were classified as Level 3B, 334 defined as standard-of-care or investigational biomarkers that predict response to an FDA335 approved or investigational drug in another cancer. Notable examples included a combined 37\% 336 prevalence of actionable TSC1/2 deletions in PECOMA, IDH1/2 alterations in 27\% of CHS, and 337 targetable PI3K pathway (PIK3CA, ATK1, MTOR, or TSC1) alterations in a collective $31 \%$ of 338 MRLS. Notably, 21\% of MRLS cases had Level 4 PTEN deletions, for which compelling 339 biological evidence supports their use as a predictive biomarker. Other intriguing Level 4 340 alterations included somatic NF1 deletions in MPNST (32\%), UPS (14\%), ERMS (14\%), and 341 PLLS (14\%), and CDKN2A deletions in many subtypes at a rate of up to $48 \%$ as seen in 342 MPNST.

\section{Discussion}

345 To better understand genetic heterogeneity in sarcomas, we analyzed prospectively generated 346 tumor next generation sequencing data from a cohort of 2,138 sarcoma samples representing 34745 histological subtypes. Across all subtypes, the most common alterations we identified were in 348 cell cycle control and TP53, receptor tyrosine kinases/PI3K/RAS, and epigenetic regulators. 349 Previously unreported subtype-specific associations included TERT amplification in intimal 350 sarcoma and SWI/SNF complex alterations in uterine adenosarcoma. Tumor mutation burden 351 varied widely between and within subtypes. 
medRxiv preprint doi: https://doi.org/10.1101/2021.10.28.21265587; this version posted October 30, 2021. The copyright holder for this preprint (which was not certified by peer review) is the author/funder, who has granted medRxiv a license to display the preprint in perpetuity.

It is made available under a CC-BY-NC-ND 4.0 International license .

352 Epigenetic pathway mutations frequently occurred in many subtypes in our cohort, in keeping 353 with an emerging recognition of epigenetic dysregulation as an important factor in the 354 pathogenesis of sarcomas (24). A common epigenetic pathway alteration was amplification of 355 NCOR1, particularly in ULMS, LMS, and OS. NCOR1 is a transcriptional corepressor that 356 regulates transcription factors specific to mesenchymal lineages and can suppress 357 differentiation when overexpressed $(31,37)$. If amplification of NCOR1 correlates with increased 358 protein levels in these sarcomas, which RNA sequencing data suggests it may, this could lead 359 to altered differentiation and transcriptional programs. Moreover, since the activity of NCOR1 is 360 modulated by PI3K/Akt-mediated control of nuclear localization, both inhibition of that pathway 361 and of HDAC3 warrant further exploration as potential therapeutic strategies in NCOR1362 amplified ULMS, LMS, or OS (38).

363 In uterine adenosarcoma, we identified genetic alterations in the SWI/SNF chromatin 364 remodeling complex in $43 \%$ of cases, mostly loss-of-function alterations in $A R I D 1 A$ or PBRM1. 365 Uterine adenosarcoma is a rare subtype composed of both sarcomatous stroma and benign 366 epithelium, which can behave aggressively, especially in the setting of sarcomatous overgrowth 367 (39). Given the role of epigenetic regulation in determining differentiation, impaired SWI/SNF 368 function could contribute to this phenotype. Histone mutations have been observed in ovarian 369 carcinosarcoma, suggesting that epigenetic dysregulation may be a common mechanism for 370 impaired lineage commitment in Müllerian tumors (40). Given synthetic lethality between the 371 loss of the SWI/SNF component SMARCB1 in epithelioid sarcoma and EZH2 inhibition with the 372 now FDA-approved drug tazemetostat, EZH2 inhibition may represent a future therapeutic 373 strategy in uterine adenosarcoma (41).

374 We also analyzed genes involved in maintenance of telomeres, whose tumor-suppressive 375 function is dependent on the silencing of TERT, a reverse transcriptase and core component of 376 telomerase. Mutations in the TERT promoter, first identified in melanoma, lead to increased 
medRxiv preprint doi: https://doi.org/10.1101/2021.10.28.21265587; this version posted October 30, 2021. The copyright holder for this preprint (which was not certified by peer review) is the author/funder, who has granted medRxiv a license to display the preprint in perpetuity.

It is made available under a CC-BY-NC-ND 4.0 International license .

377 transcription of the TERT gene $(42,43)$. Within our cohort, TERT amplification occurs in $44 \%$ of

378 intimal sarcomas, which to our knowledge has not been previously reported. Whether this

379 amplification leads to increased expression of the TERT gene product should be investigated,

380 as TERT overexpression is known to be oncogenic in certain contexts (44). In addition, our data

381 validate prior findings of TERT mutations in MLPS and SFT. However, the rate in SFT was

382 greater than observed in prior studies (45), which may be explained by differences in disease

383 aggressiveness, as TERT mutations associate with worse prognosis (46).

384 While we included $A T R X$ in the epigenetic pathway gene list owing to its fundamental role, 385 along with $D A X X$, as a histone variant H3.3 chaperone, $A T R X$ also participates in other 386 pathways including telomerase-independent alternative lengthening of telomeres (ALT), which 387 has been observed in a number of soft tissue sarcomas including UPS and liposarcoma (47). 388 Because UPS and liposarcoma also harbor TERT alterations in a largely non-overlapping 389 pattern, these sarcomas may acquire the ability to aberrantly maintain telomeres through 390 multiple independent mechanisms. In addition to epigenetic and ALT functions, ATRX helps 391 maintain genomic integrity (48). Because of the diversity of the physiologic functions of $A T R X$, 392 the role(s) of $A T R X$ alterations in sarcomagenesis are difficult to predict a priori. Thus, 393 developing tools such as patient-derived cell lines and xenografts to study the impact of these 394 alterations on $A T R X$-dependent functions will be informative. Given the relative frequency of 395 ATRX alterations and the inclusion of ATRX on MSK-IMPACT and other tumor sequencing 396 platforms, such investigations are eminently feasible.

397 Toward identifying predictive biomarkers for response to immune checkpoint blockade in 398 sarcoma, we analyzed the distribution of MSI-H and high TMB, which are associated with 399 response to these agents in other solid tumors. Almost none of the samples had microsatellite 400 instability and there were relatively few samples with high TMB. However, the upper tail of TMB 401 was relatively long in certain subtypes such as UPS, ANGS, and ULMS. Moreover, we do not 
402 yet know whether the TMB cutoff of 10 mutations per megabase, which defines high TMB for

403 carcinomas and predicts response to immune checkpoint blockade, is the appropriate threshold

404 for TMB as a predictive biomarker in mesenchymal neoplasms, let alone specific sarcoma

405 subtypes. Indeed, recent work suggests that the highest quintile of TMB within a specific cancer

406 type is associated with improved outcomes following checkpoint inhibitor therapy and, following

407 from that observation, that the TMB threshold for benefit is not absolute (49). Because both MSI

408 status (via MSIsensor) and TMB can be readily determined from targeted sequencing,

409 correlative analysis of both MSI status and TMB in sarcoma immunotherapy trials on a subtype-

410 specific basis is needed to inform our understanding.

411 Determining the clinical relevance of the landscape of genetic alterations in sarcomas described

412 herein requires a further phase of investigation. Toward improved designs of clinical trials in

413 sarcoma, which have often grouped multiple subtypes together despite significant inter- and

414 intra-subtype genetic variability, future studies should investigate which genetic alterations result

415 in functional effects. This may be particularly important in the subtypes we identified as having

416 high entropy in their genomic clustering. That knowledge will enable the establishment of

417 subtype and genotype-based trials to study the effect of novel agents in better defined biologic

418 groups of tumors. The data we present herein and via an accompanying interactive database

419 (cBioPortal link to be provided) will serve as a resource for the field to explore and compare

420 subtype-specific alterations to facilitate this transition in approach.

\section{Methods}

\section{$423 \quad$ Patient Cohort}

424 This study was approved by the Institutional Review Board at Memorial Sloan Kettering Cancer

425 Center (MSK). We identified patients with a diagnosis of soft tissue or bone sarcoma who had 
426 tumor and matched normal (white blood cell) tissue sequenced using the MSK-IMPACT assay

427 through December 19, $2019(5,18)$. Tumors were sequenced using one of 3 versions of MSK-

428 IMPACT, including 341, 410, or 468 genes, with results reported in the medical record. In

429 patients with multiple samples, only one sample was included in the cohort; those collected

430 earliest and of highest purity and highest average coverage were selected in that order of

431 priority. Clinical characteristics such as patient age, sex, race, and metastatic versus primary

432 site, were annotated per the standard MSK-IMPACT workflow (18).

433 Histologic Analysis

434 Histologic diagnosis was annotated according to the standard MSK-IMPACT workflow. In the

435 case of sarcomas characterized by canonical fusion events, the medical record was queried to

436 ensure that the appropriate fusion event was detected and if not, the sample was reviewed with

437 the assistance of an expert sarcoma pathologist. Similarly, samples harboring a canonical

438 fusion but with a discordant pathologic diagnosis were further reviewed to assign the most

439 appropriate diagnosis. Fusions other than those identified by MSK-IMPACT were annotated at

440 the patient (not sample) level. Samples originally annotated as sarcoma or round cell sarcoma

441 not otherwise specified, rhabdomyosarcoma (without further classification), spindle cell

442 rhabdomyosarcoma, and fibrosarcoma underwent additional medical record review and, in

443 some cases, pathology review to render the most accurate diagnosis possible. In some

444 additional cases with ambiguity in subtype assignment, the diagnosis was updated upon further

445 review by an expert pathologist. We further standardized diagnoses by mapping each tumor to a

446 unique code from the OncoTree ontology (50) except for round cell sarcoma other (RCS (other))

447 and extraskeletal osteosarcoma, which were categories created for this study. Samples that

448 could not be assigned to one of the Oncotree codes $(n=243)$ were excluded from our analysis

449 cohort. 
medRxiv preprint doi: https://doi.org/10.1101/2021.10.28.21265587; this version posted October 30, 2021. The copyright holder for this preprint (which was not certified by peer review) is the author/funder, who has granted medRxiv a license to display the preprint in perpetuity.

It is made available under a CC-BY-NC-ND 4.0 International license .

451 Genomic alterations were annotated using the OncoKB precision oncology knowledge base, 452 which identifies functionally relevant cancer variants and their potential clinical actionability (36). 453 Except where otherwise specified in the text, variants of unknown significance, i.e. not labeled 454 as oncogenic, likely oncogenic, or predicted oncogenic in OncoKB were excluded from the 455 analysis. Therapeutically targetable somatic alterations were labeled using levels of clinical 456 actionability defined in OncoKB, which range from level 1, FDA-recognized biomarkers of 457 response to FDA-approved drugs, to level 4, biomarkers of hypothetical relevance based on 458 compelling preclinical biological evidence. Analyses of alterations in oncogenic signaling 459 pathways were performed using the set of pathway definitions previously curated by our group, 460 which we expanded to include the DDR and epigenetic modifier pathways using additional 461 templates curated from literature subtypes (24,51-53).

462 Tumor mutation burden (TMB) was computed as the total number of nonsynonymous mutations 463 divided by the total number of base pairs sequenced per sample. The fraction of the genome 464 altered (FGA) was defined as the fraction of genome with $\log _{2}$ copy number gain $>0.2$ or loss < $465-0.2$ relative to the size of the genome for which copy number was profiled. We computed 466 MSIsensor scores for all samples in the cohort and used a threshold of MSIsensor score $\geq 10$ to 467 identify tumors with microsatellite instability (MSI-high) (54). MSI-high was confirmed by a PCR468 based assay (Idylla). MSIsensor $\geq 3$ and $<10$ were labeled indeterminate and samples that did 469 not meet quality control for assigning MSI status were labeled do not report (DNR).

470 Allele-specific copy number estimates at both the gene and chromosome arm levels were 471 computed using the FACETS (Fraction and Allele-Specific Copy Number Estimates from Tumor 472 Sequencing) algorithm, which also provided purity-corrected segmentation files and allowed 473 identification of whole-genome duplication events (55). FACETS output was also used to infer 
474 the cancer cell fraction associated with individual mutations for clonality analyses. Significantly

475 recurrently mutated genes were identified using the MuSic and MutSigCV 1.4 algorithms, with a

476 threshold q-value of 0.1 (56,57). Dimensionality reduction was performed using Uniform

477 Manifold Approximation and Projection (UMAP) (http://arxiv.org/abs/1802.03426) and clusters

478 were identified using Hierarchical Density-Based Spatial Clustering of Applications with Noise

479 (HDBSCAN) (58). Shannon entropy was calculated from observed cluster assignment by

480 subtype and reported in natural units.

481 Mutational signatures for samples with $\geq 15$ synonymous and nonsynonymous single nucleotide 482 variants (SNVs) were extracted using the COSMIC v3 catalog of exome reference signatures 483 and default parameters (59) (https://github.com/mskcc/tempoSig). For mutational signatures to 484 be considered detectable, we required a $p$-value $<0.05$ and a minimum of 1 observed mutation 485 attributed to the signature, where the number of observed mutations was defined as the 486 observed mutational signature fraction multiplied by the number of SNVs per sample.

487 Data Availability

488 All clinical and genomic data described in this manuscript will be accessible online and publicly 489 available for bulk download through the cBioPortal for Cancer Genomics (60).

$491 \quad$ Author contributions

492 Conception and design: Nacev, Sanchez-Vega, Gounder, Bowler, Singer, Tap

493 Development of methodology: Nacev, Sanchez-Vega, Smith, Shi, Tang, Socci

494 Data collection: Nacev, Antonescu, Zehir, Gounder, Chi, D’Angelo, Dickson, Kelly, Keohan, 495 Movva, Thornton, Meyers, Wexler, Slotkin, Glade Bender, Shukla, Hensley, Healey, La

496 Quaglia, Crago, Yoon, Untch, Chiang, Agaram, Hameed, Berger, Solit, Ladanyi, Singer, Tap 
Analysis and interpretation of data: Nacev, Sanchez-Vega, Smith, Antonescu, Rosenbaum, Shi,

502 Drafting the manuscript - Nacev, Sanchez-Vega, Rosenbaum, Singer, Tap

503 Review and revision of the manuscript: All authors

504 Visualization of data: Sanchez-Vega, Smith, Shi, Tang

505 Study supervision and funding acquisition: Singer, Tap

\section{Competing interests}

508 MMG has served on advisory boards for Athenex, Ayala, Bayer, Boehringer Ingelheim, Daiichi

509 Sankyo, Epizyme, Karyopharm, Rain, SpringWorks Therapeutics, Tracon, and TYME

510 Technologies; provides consulting services through Guidepoint, GLG Pharma, Third Bridge, and

511 Flatiron Health; has received speaking honoraria from Medscape, More Health, Physicians

512 Education Resource and touchIME; receives publishing royalties from Wolters Kluwer; holds a

513 patent for a patient-reported outcome tool licensed through the institution; and has performed

514 research without compensation in collaboration with Foundation Medicine. TGB is currently

515 employed by Pfizer. PC has served on advisory boards or consulted for Deciphera, Exelixis,

516 NingboNewBay Medical Technology, Novartis, and Zai Lab, and has received institutional

517 research funding from Deciphera, Ningbo NewBay Medical Technology, Novartis, and

518 Pfizer/Array. SPD has received institutional research funding from Amgen, Bristol Meyers

519 Squibb, Deciphera, EMD Serono, Incyte, Merck, and Nektar Therapeutics, has served as a

520 consultant or on advisory boards for Adaptimmune, Amgen, EMD Serono, GlaxoSmithKline,

521 Immune Design, Immunocore, Incyte, Merck, and Nektar Therapeutics, and has served on data 
medRxiv preprint doi: https://doi.org/10.1101/2021.10.28.21265587; this version posted October 30, 2021. The copyright holder for this preprint (which was not certified by peer review) is the author/funder, who has granted medRxiv a license to display the preprint in perpetuity.

It is made available under a CC-BY-NC-ND 4.0 International license .

522 safety monitoring boards for Adaptimmune, GlaxoSmithKline, Merck, and Nektar Therapeutics.

523 MAD has received institutional research funding from Aadi Bioscience and Eli Lilly. CMK has

524 received research funding from Amgen, Exicure, Incyte, Kartos, Merck, Servier, and Xencor;

525 has consulted for Exicure and Kartos; and has served on dvisory boards for Immunicum. SM

526 has received research funding from Ascentage Pharma and Hutchison Medi Pharma. KT has

527 served as a consultant for Epizyme and GlaxoSmithKline. PAM has served on advisory boards

528 or consulted for Margaux Miracle Foundation, Salarius Pharmaceuticals, and Takeda, and has

529 an immediate family member who has served on advisory boards or consulted for Boehringer

530 Ingelheim and Genentech and received honoraria from Eastern Pulmonary Conference. JLGB

531 has received institutional research support from Amgen, Bayer, Bristol Myers Squibb, Celgene,

532 Cellectar Biosciences, Eisai, Ignyta, Lilly, Loxo Oncology, Merck, Novartis, and Roche; and

533 served on data safety monitoring boards for Abbvie, Merck, and SpringWorks and on an

534 advisory board for Bristol Myers Squibb. MLH has served on advisory boards and consulted for

535 Eli Lilly, GlaxoSmithKline, and Thrive Bioscience, received author royalties from UpToDate, and

536 received speaker honoraria from Research to Practice; her spouse is employed by Sanofi. JHH

537 has consulted for Daiichi Sankyo and Stryker and is a trustee of the Musculoskeletal Transplant

538 Foundation. AC has served on an advisory board for SpringWorks. BRU is co-inventor of

539 intellectual property (HRAS as a biomarker of tipifarnib efficacy) that has been licensed by MSK

540 to Kura Oncology. SC has consulted for AstraZeneca. MFB has served as a consultant for Eli

541 Lilly and PetDx. WDT has served on advisory boards for Agios Pharmaceuticals, Bayer,

542 Blueprint Medicines, C4 Therapeutics, Certis Oncology Solutions (in which he also owns stock),

543 Daiichi Sankyo, Deciphera, EMD Serono, Epizyme, Innova Therapeutics, Medpacto,

544 Mundipharma, and NanoCarrier, and has provided consulting services for Adcendo, Ayala

545 Pharmaceuticals, Cogent Biosciences, Kowa, and Servier, holds two patents for biomarkers of

546 CDK4 inhibitor efficacy in cancer, and is a co-founder of and owns stock in Atropos

547 Therapeutics. DBS has consulted for BridgeBio, FORE Therapeutics, Loxo/Lilly Oncology, 
medRxiv preprint doi: https://doi.org/10.1101/2021.10.28.21265587; this version posted October 30, 2021. The copyright holder for this preprint (which was not certified by peer review) is the author/funder, who has granted medRxiv a license to display the preprint in perpetuity.

548 Pfizer, Scorpion Therapeutics, and Vividion Therapeutics. All author authors have no financial

549 relationships to disclose. 


\section{References}

551 1. Siegel RL, Miller KD, Jemal A. Cancer statistics, 2018. CA Cancer J Clin 2018;68(1):7-

$552 \quad 30$ doi $10.3322 /$ caac.21442.

$5532 . \quad$ WHO. Soft tissue and bone tumours. Lyon (France): International Agency for Research $554 \quad$ on Cancer; 2020.

555 3. Schaefer IM, Cote GM, Hornick JL. Contemporary Sarcoma Diagnosis, Genetics, and $556 \quad$ Genomics. J Clin Oncol 2018;36(2):101-10 doi 10.1200/JCO.2017.74.9374.

557 4. Cancer Genome Atlas Research N. Comprehensive and Integrated Genomic 558 Characterization of Adult Soft Tissue Sarcomas. Cell 2017;171(4):950-65 e28 doi $559 \quad$ 10.1016/j.cell.2017.10.014.

560 5. Cheng DT, Mitchell TN, Zehir A, Shah RH, Benayed R, Syed A, et al. Memorial Sloan $561 \quad$ Kettering-Integrated Mutation Profiling of Actionable Cancer Targets (MSK-IMPACT): A $562 \quad$ Hybridization Capture-Based Next-Generation Sequencing Clinical Assay for Solid $563 \quad$ Tumor Molecular Oncology. J Mol Diagn 2015;17(3):251-64 doi

$564 \quad$ 10.1016/j.jmoldx.2014.12.006.

$565 \quad 6 . \quad$ von Mehren M, Joensuu H. Gastrointestinal Stromal Tumors. J Clin Oncol $566 \quad$ 2018;36(2):136-43 doi 10.1200/JCO.2017.74.9705.

567 7. Schaefer IM, Wang Y, Liang CW, Bahri N, Quattrone A, Doyle L, et al. MAX inactivation is an early event in GIST development that regulates p16 and cell proliferation. Nat

570 8. Agelopoulos K, Richter GH, Schmidt E, Dirksen U, von Heyking K, Moser B, et al. Deep 571 Sequencing in Conjunction with Expression and Functional Analyses Reveals Activation $572 \quad$ of FGFR1 in Ewing Sarcoma. Clin Cancer Res 2015;21(21):4935-46 doi 10.1158/10780432.CCR-14-2744. 
574 9. Perot G, Croce S, Ribeiro A, Lagarde P, Velasco V, Neuville A, et al. MED12 alterations in both human benign and malignant uterine soft tissue tumors. PLoS One

10. Tan MC, Brennan MF, Kuk D, Agaram NP, Antonescu CR, Qin LX, et al. Histologybased Classification Predicts Pattern of Recurrence and Improves Risk Stratification in

11. Agaram NP, Zhang L, Sung YS, Singer S, Stevens T, Prieto-Granada CN, et al. GLI1amplifications expand the spectrum of soft tissue neoplasms defined by GLI1 gene

12. Bielski CM, Zehir A, Penson AV, Donoghue MTA, Chatila W, Armenia J, et al. Genome doubling shapes the evolution and prognosis of advanced cancers. Nat Genet 2018;50(8):1189-95 doi 10.1038/s41588-018-0165-1.

587 13. Oliner JD, Kinzler KW, Meltzer PS, George DL, Vogelstein B. Amplification of a gene encoding a p53-associated protein in human sarcomas. Nature 1992;358(6381):80-3 doi

590 14. Singer S, Socci ND, Ambrosini G, Sambol E, Decarolis P, Wu Y, et al. Gene expression profiling of liposarcoma identifies distinct biological types/subtypes and potential

594 15. Chmielecki J, Crago AM, Rosenberg M, O'Connor R, Walker SR, Ambrogio L, et al. Nat Genet 2010;42(8):715-21 doi 10.1038/ng.619. 
17. George S, Miao D, Demetri GD, Adeegbe D, Rodig SJ, Shukla S, et al. Loss of PTEN Is Associated with Resistance to Anti-PD-1 Checkpoint Blockade Therapy in Metastatic Uterine Leiomyosarcoma. Immunity 2017;46(2):197-204 doi 10.1016/j.immuni.2017.02.001.

604 18. Zehir A, Benayed R, Shah RH, Syed A, Middha S, Kim HR, et al. Mutational landscape of metastatic cancer revealed from prospective clinical sequencing of 10,000 patients. Nat Med 2017;23(6):703-13 doi 10.1038/nm.4333.

19. Bode-Lesniewska B, Zhao J, Speel EJ, Biraima AM, Turina M, Komminoth P, et al. Gains of $12 q 13-14$ and overexpression of mdm2 are frequent findings in intimal sarcomas of the pulmonary artery. Virchows Arch 2001;438(1):57-65 doi

20. Ballinger ML, Goode DL, Ray-Coquard I, James PA, Mitchell G, Niedermayr E, et al. Monogenic and polygenic determinants of sarcoma risk: an international genetic study.

614 21. Le DT, Durham JN, Smith KN, Wang H, Bartlett BR, Aulakh LK, et al. Mismatch repair deficiency predicts response of solid tumors to PD-1 blockade. Science 2017;357(6349):409-13 doi 10.1126/science.aan6733.

617 22. Lord CJ, Ashworth A. PARP inhibitors: Synthetic lethality in the clinic. Science 2017;355(6330):1152-8 doi 10.1126/science.aam7344.

619 23. Hensley ML, Chavan SS, Solit DB, Murali R, Soslow R, Chiang S, et al. Genomic 620 Landscape of Uterine Sarcomas Defined through Prospective Clinical Sequencing. Clin $621 \quad$ Cancer Res 2020 doi 10.1158/1078-0432.CCR-19-3959.

622 24. Nacev BA, Jones KB, Intlekofer AM, Yu JSE, Allis CD, Tap WD, et al. The epigenomics 623 of sarcoma. Nat Rev Cancer 2020 doi 10.1038/s41568-020-0288-4. 
624 25. Cermakova K, Hodges HC. Next-Generation Drugs and Probes for Chromatin Biology:

26. Shern JF, Chen L, Chmielecki J, Wei JS, Patidar R, Rosenberg M, et al. Comprehensive genomic analysis of rhabdomyosarcoma reveals a landscape of alterations affecting a

27. Doros L, Yang J, Dehner L, Rossi CT, Skiver K, Jarzembowski JA, et al. DICER1 mutations in embryonal rhabdomyosarcomas from children with and without familial PPB-tumor predisposition syndrome. Pediatr Blood Cancer 2012;59(3):558-60 doi 10.1002/pbc.24020.

28. Taylor BS, DeCarolis PL, Angeles CV, Brenet F, Schultz N, Antonescu CR, et al.

29. Suehara Y, Alex D, Bowman A, Middha S, Zehir A, Chakravarty D, et al. Clinical structurally rearranged liposarcomas. Cancer Discov 2011;1(7):587-97 doi

643 30. Mottis A, Mouchiroud L, Auwerx J. Emerging roles of the corepressors NCoR1 and SMRT in homeostasis. Genes Dev 2013;27(8):819-35 doi 10.1101/gad.214023.113.

645 31. Yamamoto H, Williams EG, Mouchiroud L, Canto C, Fan W, Downes M, et al. NCoR1 is a conserved physiological modulator of muscle mass and oxidative function. Cell 2011;147(4):827-39 doi 10.1016/j.cell.2011.10.017. 
32. Agaram NP, Zhang L, LeLoarer F, Silk T, Sung YS, Scott SN, et al. Targeted exome sequencing profiles genetic alterations in leiomyosarcoma. Genes Chromosomes

33. D'Angelo SP, Mahoney MR, Van Tine BA, Atkins J, Milhem MM, Jahagirdar BN, et al. Nivolumab with or without ipilimumab treatment for metastatic sarcoma (Alliance

34. Tawbi HA, Burgess M, Bolejack V, Van Tine BA, Schuetze SM, Hu J, et al. Pembrolizumab in advanced soft-tissue sarcoma and bone sarcoma (SARC028): a multicentre, two-cohort, single-arm, open-label, phase 2 trial. Lancet Oncol

35. Rizvi NA, Hellmann MD, Snyder A, Kvistborg P, Makarov V, Havel JJ, et al. Cancer immunology. Mutational landscape determines sensitivity to PD-1 blockade in non-small cell lung cancer. Science 2015;348(6230):124-8 doi 10.1126/science.aaa1348.

36. Chakravarty D, Gao J, Phillips SM, Kundra R, Zhang H, Wang J, et al. OncoKB: A

37. Park DM, Li J, Okamoto H, Akeju O, Kim SH, Lubensky I, et al. N-CoR pathway targeting induces glioblastoma derived cancer stem cell differentiation. Cell Cycle 2007;6(4):467-70 doi 10.4161/cc.6.4.3856.

38. Hermanson O, Jepsen K, Rosenfeld MG. N-CoR controls differentiation of neural stem cells into astrocytes. Nature 2002;419(6910):934-9 doi 10.1038/nature01156. adenosarcoma: an analysis on management, outcomes, and risk factors for recurrence. Gynecol Oncol 2014;135(3):455-61 doi 10.1016/j.ygyno.2014.10.022. 
673 40. Zhao S, Bellone S, Lopez S, Thakral D, Schwab C, English DP, et al. Mutational landscape of uterine and ovarian carcinosarcomas implicates histone genes in epithelialmesenchymal transition. Proc Natl Acad Sci U S A 2016;113(43):12238-43 doi 10.1073/pnas.1614120113.

677 41. Gounder M, Schöffski P, Jones RL, Agulnik M, Cote GM, Villalobos VM, et al. Tazemetostat in advanced epithelioid sarcoma with loss of INI1/SMARCB1: an international, open-label, phase 2 basket study. Lancet Oncol 2020;21(11):1423-1432

681 42. Horn S, Figl A, Rachakonda PS, Fischer C, Sucker A, Gast A, et al. TERT promoter mutations in familial and sporadic melanoma. Science 2013;339(6122):959-61 doi 10.1126/science.1230062.

43. Huang FW, Hodis E, Xu MJ, Kryukov GV, Chin L, Garraway LA. Highly recurrent TERT promoter mutations in human melanoma. Science 2013;339(6122):957-9 doi 10.1126/science.1229259.

687 44. Peifer M, Hertwig F, Roels F, Dreidax D, Gartlgruber M, Menon R, et al. Telomerase activation by genomic rearrangements in high-risk neuroblastoma. Nature 2015;526(7575):700-4 doi 10.1038/nature14980.

45. Campanella NC, Penna V, Abrahao-Machado LF, Cruvinel-Carloni A, Ribeiro G, Soares

693 46. Bahrami A, Lee S, Schaefer IM, Boland JM, Patton KT, Pounds S, et al. TERT promoter 694 mutations and prognosis in solitary fibrous tumor. Mod Pathol 2016;29(12):1511-22 doi $695 \quad 10.1038 /$ modpathol.2016.126.

696 47. Henson JD, Hannay JA, McCarthy SW, Royds JA, Yeager TR, Robinson RA, et al. A 697 robust assay for alternative lengthening of telomeres in tumors shows the significance of 

2005;11(1):217-25.

48. Huh MS, Ivanochko D, Hashem LE, Curtin M, Delorme M, Goodall E, et al. Stalled replication forks within heterochromatin require ATRX for protection. Cell Death Dis

49. Samstein RM, Lee $\mathrm{CH}$, Shoushtari AN, Hellmann MD, Shen R, Janjigian YY, et al. Tumor mutational load predicts survival after immunotherapy across multiple cancer

50. Kundra R, Zhang H, Sheridan R, Sirintrapun SJ, Wang A, Ochoa A, et al. OncoTree: A

51. Sanchez-Vega F, Mina M, Armenia J, Chatila WK, Luna A, La KC, et al. Oncogenic

52. Nacev BA, Feng L, Bagert JD, Lemiesz AE, Gao J, Soshnev AA, et al. The expanding landscape of 'oncohistone' mutations in human cancers. Nature 2019;567(7749):473-8 doi 10.1038/s41586-019-1038-1.

53. Rosenbaum E, Jonsson P, Seier K, Qin LX, Chi P, Dickson M, et al. Clinical Outcome of Leiomyosarcomas With Somatic Alteration in Homologous Recombination Pathway Genes. JCO Precis Oncol 2020;4 doi 10.1200/PO.20.00122.

54. Middha S, Zhang L, Nafa K, Jayakumaran G, Wong D, Kim HR, et al. Reliable PanCancer Microsatellite Instability Assessment by Using Targeted Next-Generation Sequencing Data. JCO Precis Oncol 2017;2017 doi 10.1200/PO.17.00084.

721 55. Shen R, Seshan VE. FACETS: allele-specific copy number and clonal heterogeneity analysis tool for high-throughput DNA sequencing. Nucleic Acids Res 2016;44(16):e131 doi 10.1093/nar/gkw520. 
724 56. Dees ND, Zhang Q, Kandoth C, Wendl MC, Schierding W, Koboldt DC, et al. MuSiC: identifying mutational significance in cancer genomes. Genome Res 2012;22(8):1589-98 doi 10.1101/gr.134635.111.

727 57. Lawrence MS, Stojanov P, Polak P, Kryukov GV, Cibulskis K, Sivachenko A, et al. Mutational heterogeneity in cancer and the search for new cancer-associated genes. Nature 2013;499(7457):214-8 doi 10.1038/nature12213.

730 58. Campello RJGB, Moulavi D, Sander J. Density-Based Clustering Based on Hierarchical Density Estimates. Advances in Knowledge Discovery and Data Mining; 2013; Berlin, Heidelberg. Springer Berlin Heidelberg. p 160-72. (Advances in Knowledge Discovery and Data Mining).

734 59. Alexandrov LB, Kim J, Haradhvala NJ, Huang MN, Tian Ng AW, Wu Y, et al. The repertoire of mutational signatures in human cancer. Nature 2020;578(7793):94-101 doi 10.1038/s41586-020-1943-3.

737 60. Cerami E, Gao J, Dogrusoz U, Gross BE, Sumer SO, Aksoy BA, et al. The cBio cancer 738 genomics portal: an open platform for exploring multidimensional cancer genomics data. 739 Cancer Discov 2012;2(5):401-4 doi 10.1158/2159-8290.CD-12-0095. 


\section{Supplementary Tables}

743 Supplementary Table 1. Master sample dataset. MSI, microsatellite instability; FGA, fraction of

744 the genome altered; OS, overall survival; FACETS, Fraction and Allele-Specific Copy Number

745 Estimates from Tumor Sequencing algorithm; QC, quality control; CNA, copy number

746 alterations; WGD, whole genome doubling.

747 Supplementary Table 2. Patient characteristics by subtype.

748 Supplementary Table 3. Number of oncogenic fusion events in individual genes in each

749 subtype.

750 Supplementary Table 4. Pathway gene composition. CC, cell cycle; EPI, epigenetic.

751 Supplementary Table 5. Biochemical function/complex assignments for epigenetic pathway 752 genes. 
OncoTree Survival

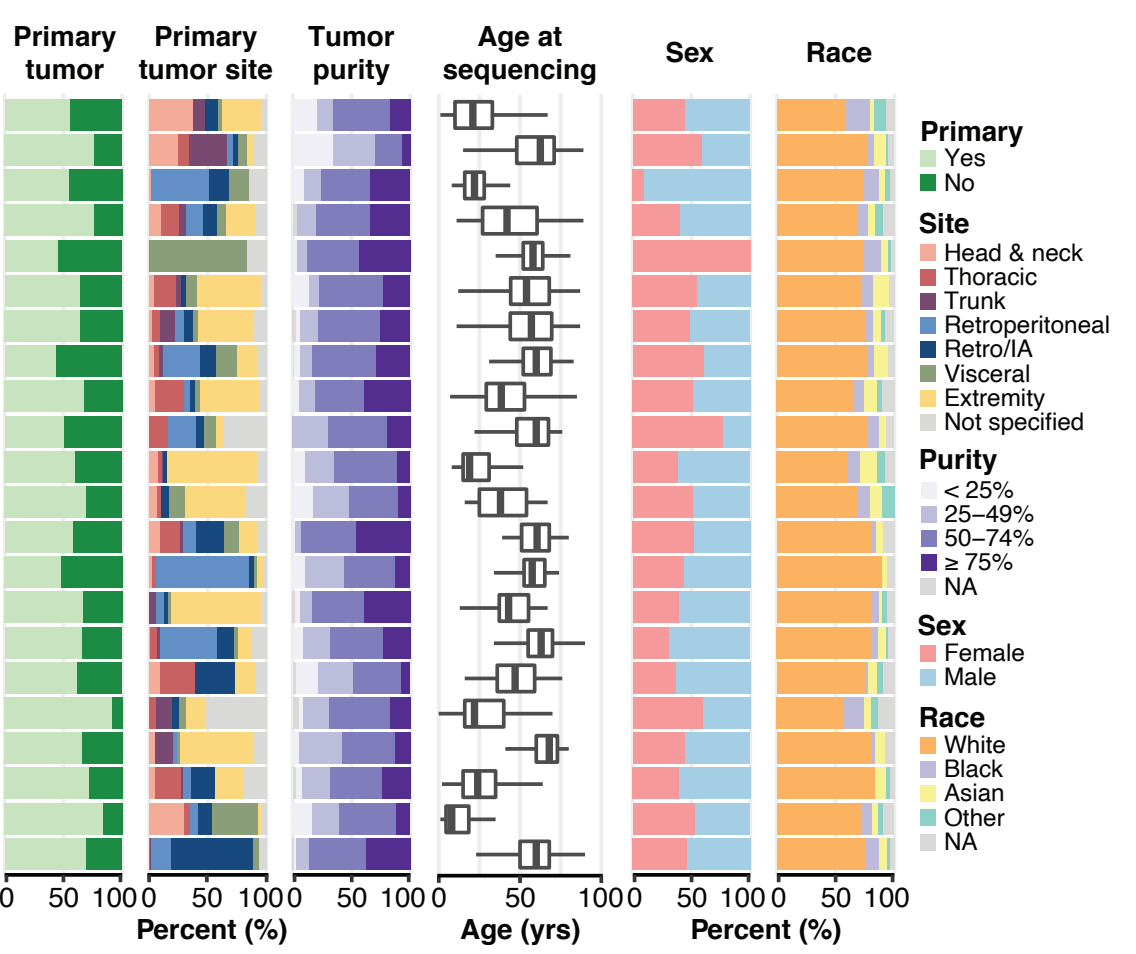

B

ARMS

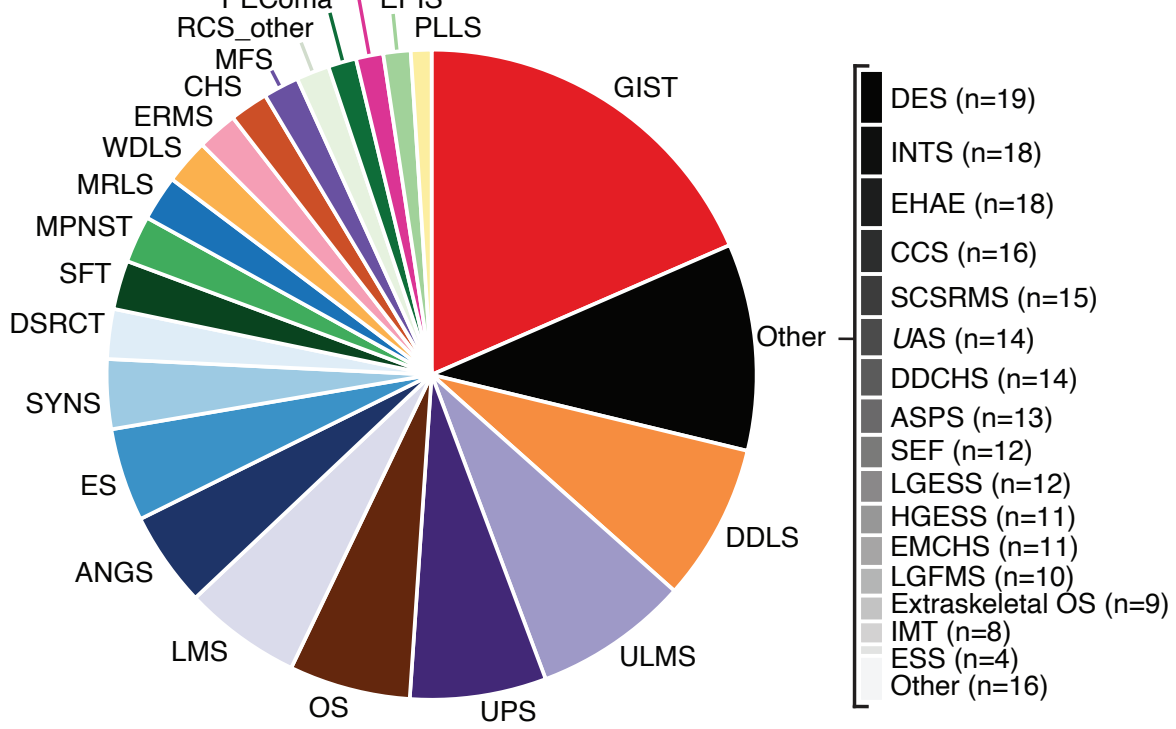

C

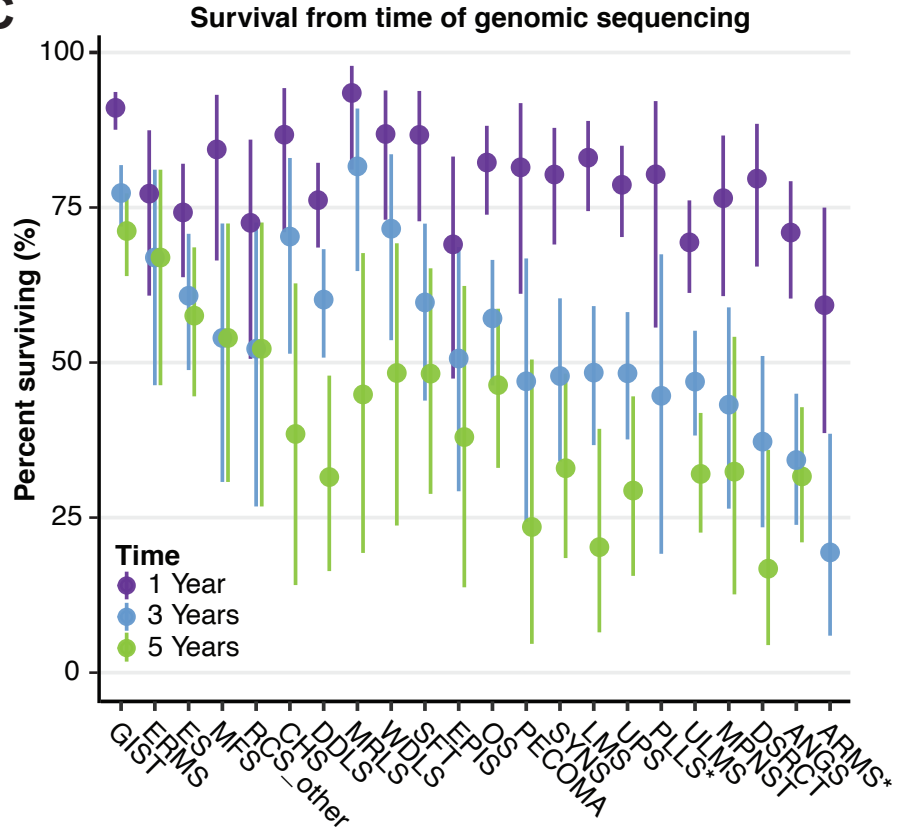

Figure 1. Sample and patient characteristics. This analysis includes 2,138 bone and soft tissue sarcoma samples, each from distinct patients. Subtypes with $\geq 20$ samples in the dataset are displayed. A, Distribution of number of samples, survival from time of sequencing, sample type (primary or metastatic site), tumor site, sample purity, age, sex, and race in each subtype. B, Overall distribution of sample number for the entire cohort. C, 1,3, and 5-year survival from the time of sequencing. ${ }^{*}, 5$-year survival $=0$. DES, desmoid tumor; ESS, endometrial stromal sarcoma; INT, intimal sarcoma; LGFMS, low-grade fibromyxoid sarcoma; EMCHS, extraskeletal myxoid chondrosarcoma; HGESS, high-grade endometrial stromal sarcoma; LGESS, low-grade endometrial stromal sarcoma; SEF, sclerosing epithelioid fibrosarcoma; ASPS, alveolar soft part sarcoma; DDCHS, dedifferentiated chondrosarcoma; UAS, uterine adenosarcoma; SCSRMS, spindle cell/sclerosing rhabdomyosarcoma; CCS, clear cell sarcoma; EHAE, epithelioid hemangioendothelioma. 

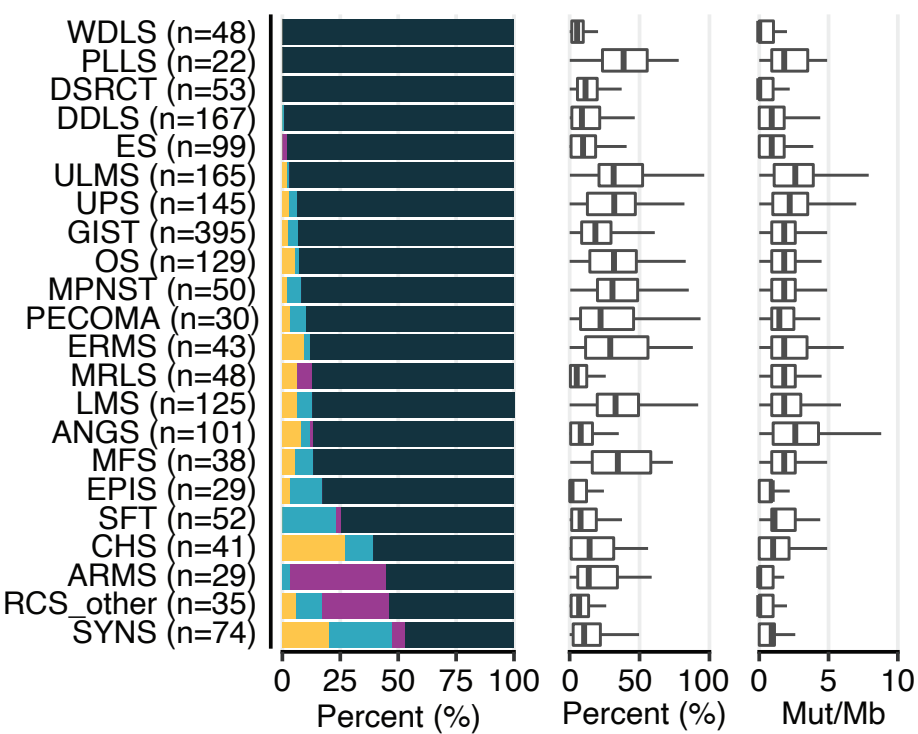

Detected alteration $\square \geq 1$ driver (IMPACT) $\quad$ Fusion (other) (source) VUS only (IMPACT) No alt detected

C

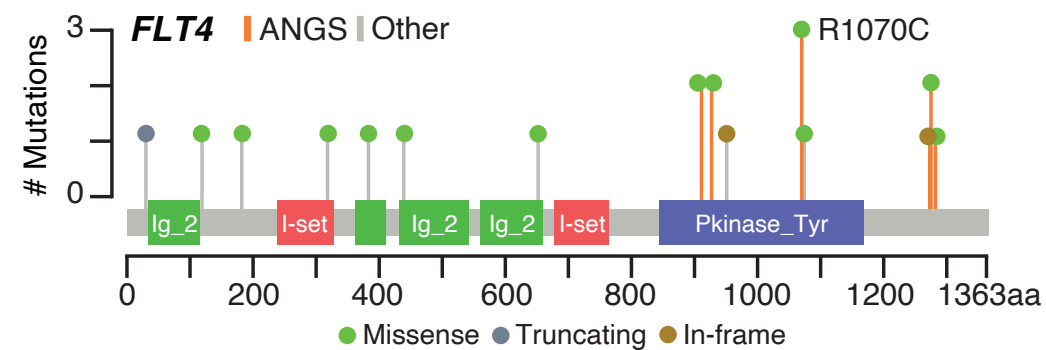

D
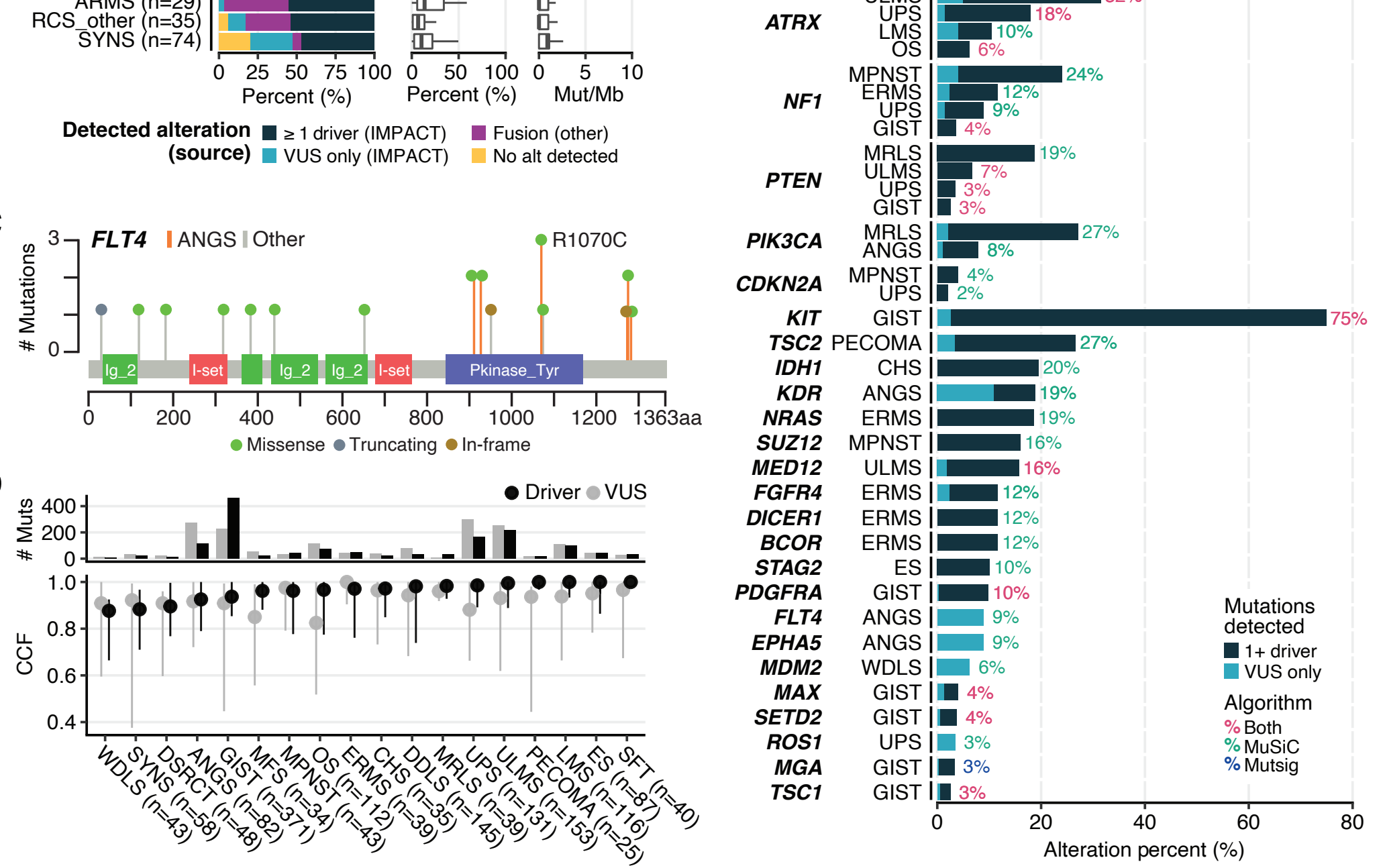

Figure 2. Mutation analysis by subtype. A, Alteration type and frequency, fraction of the genome altered (FGA) and tumor mutation burden (TMB) by subtype. Oncogenic fusions detected by MSK-IMPACT are classified as drivers. B, Significant mutations were identified in all subtypes with $n \geq 20$ in our dataset using both MutSig and MuSiC analysis. Percentages indicate the percentage of samples with an oncogenic mutation in the corresponding gene. C, FLT4 mutation type, frequency, and location in ANGS vs. other subtypes. D, Cancer cell fraction (CCF) and number of mutations for driver mutations and VUS by subtype. 
A

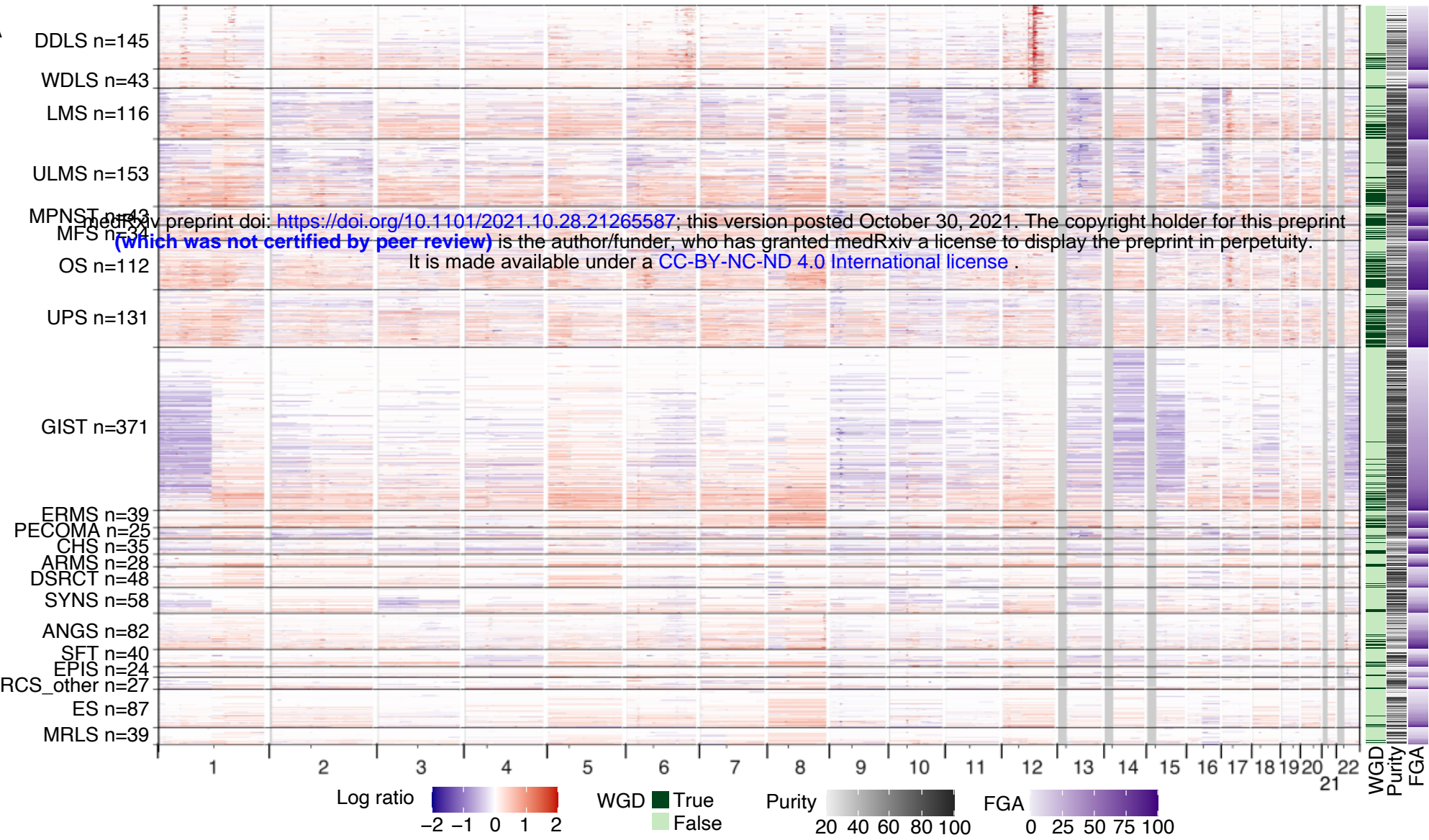

B
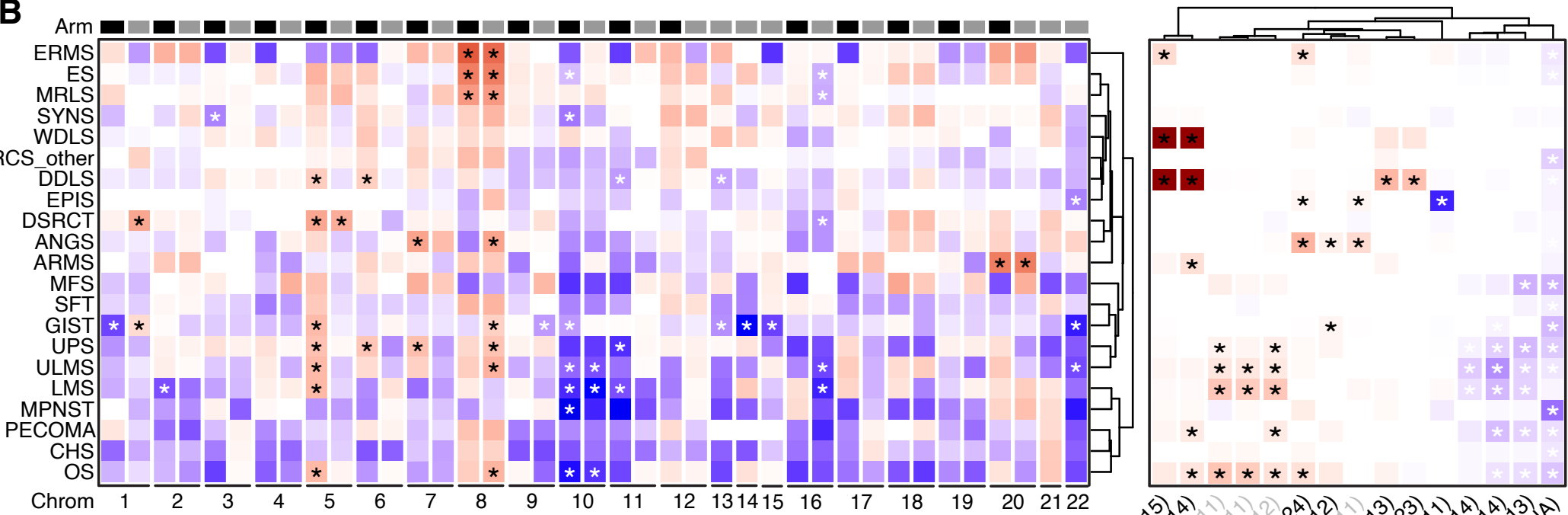

Arm $\square \mathrm{p} \square \mathrm{q}$

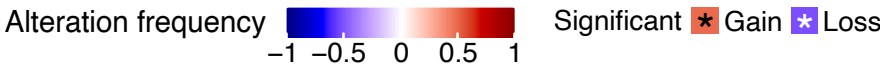

Gene-level CNA classification: Oncogenic
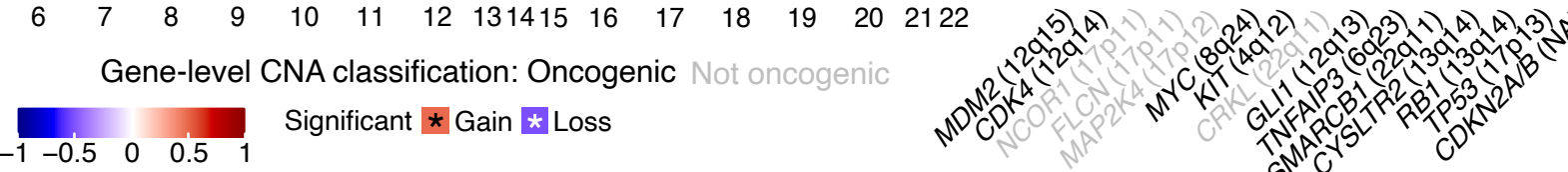

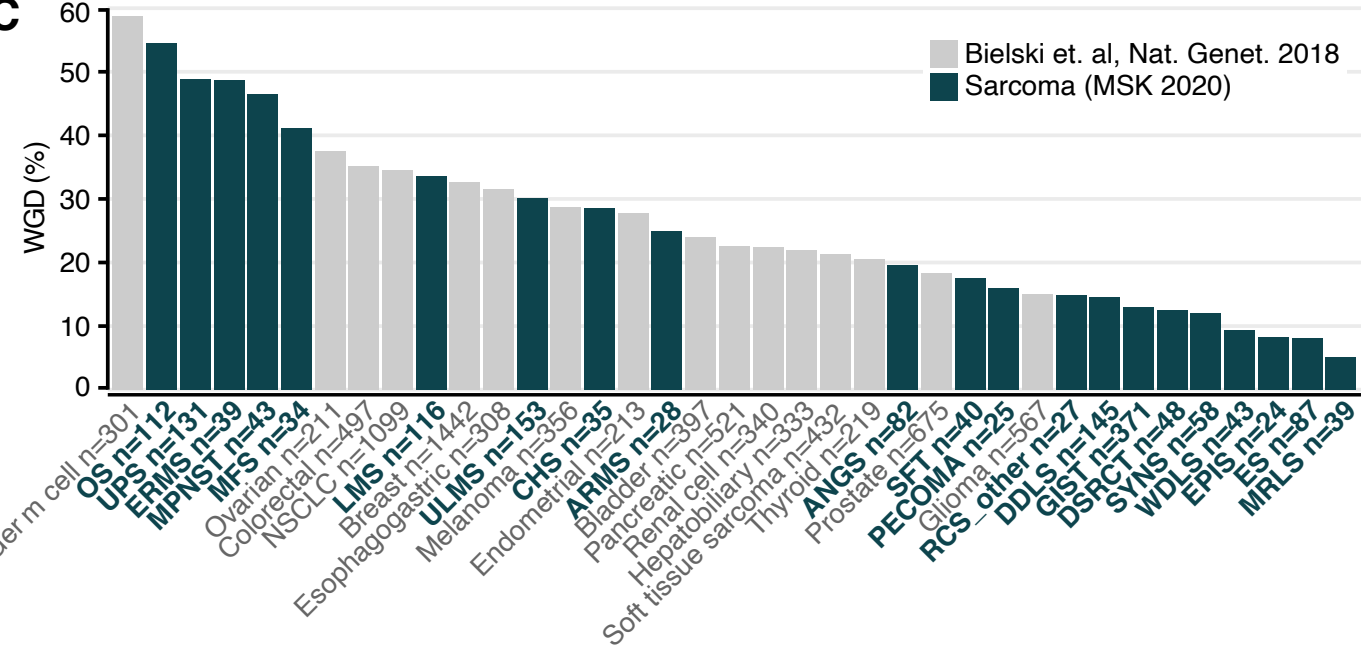

D

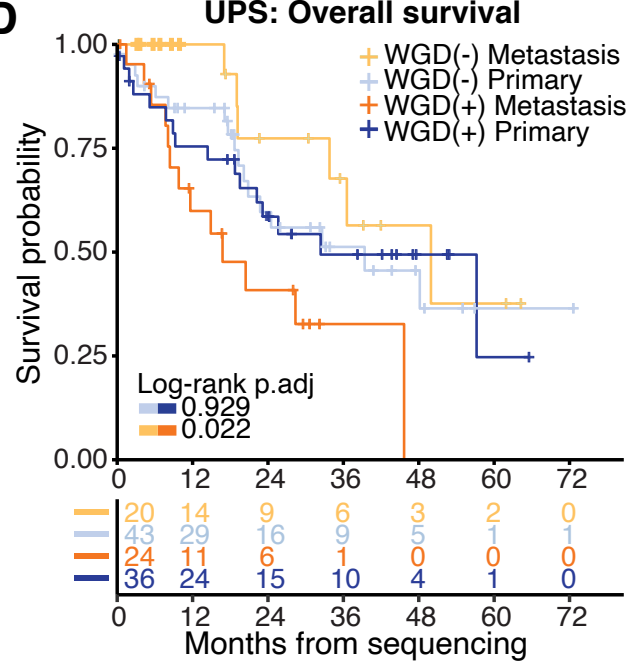

Figure 3. Copy number changes by subtype. A, Individual sample copy number variation (CNV) across the genome for each subtype. Whole genome doubling (WGD), fraction genome altered (FGA), and purity are shown at right. B, Aggregate arm-level (left) and gene-level events (right) grouped by subtype. *, significant change based on Bonferroni corrected p-values. Oncogenic vs. non-oncogenic CNV classifications according to OncoKB. C, Frequency of WGD by subtype (green) compared to other cancers with $\geq 200$ samples available for comparison (gray) (12). D, Overall survival based on WGD status within primary and metastatic samples. 
A $\left.\begin{array}{r}100 \\ 50\end{array}\right]$

50.

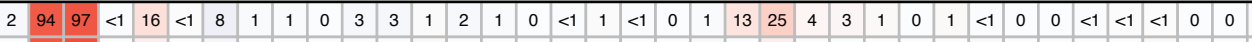

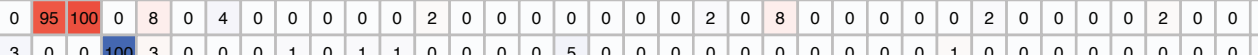

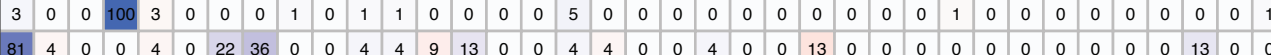

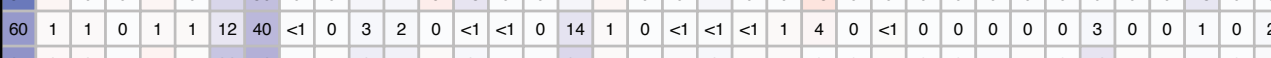

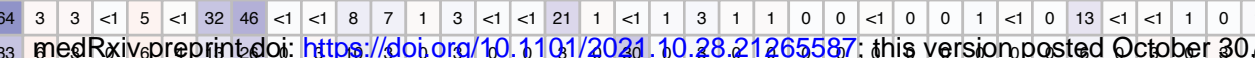

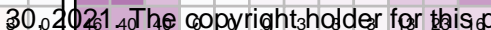

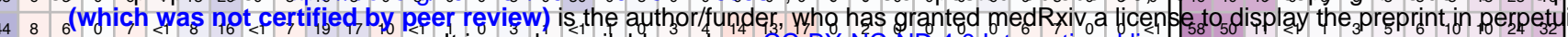

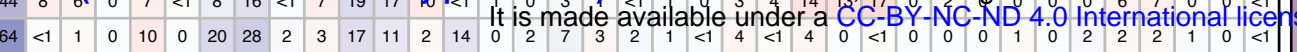

$50 \begin{array}{lllllllllllllllllllllllllllllllllllllllllll}50 & 0 & 0 & 2 & 0 & 15 & 15 & 0 & 0 & 23 & 21 & 0 & 10 & 0 & 0 & 2 & 0 & 0 & 0 & 0 & 7 & 0 & 0 & 2 & 0 & 0 & 0 & 2 & 0 & 0 & 2 & 0 & 0 & 0 & 0 & 0 \\ 5\end{array}$

$\begin{array}{lllllllllllllllllllllllllllllllllllllllllllllll}3 & 10 & 3 & 0 & 0 & 86 & 0 & 3 & 0 & 0 & 3 & 3 & 0 & 0 & 0 & 0 & 0 & 3 & 0 & 0 & 0 & 0 & 3 & 0 & 3 & 3 & 0 & 6 & 0 & 0 & 13 & 3 & 0 & 0 & 0 & 0 & 0 \\ 2 & & \end{array}$

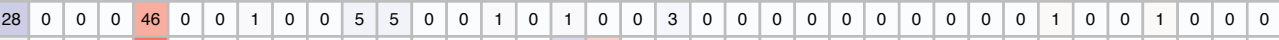

$\begin{array}{llllllllllllllllllllllllllllllllllllllllllll}6 & 0 & 0 & 0 & 79 & 0 & 0 & 0 & 0 & 0 & 0 & 0 & 0 & 0 & 0 & 0 & 20 & 25 & 0 & 0 & 0 & 0 & 0 & 0 & 0 & 0 & 0 & 0 & 0 & 0 & 0 & 0 & 0 & 0 & 0 & 0 & 0 \\ 0 & 0 & 0 & 0 & 0 & 0 & 0 & 0 & & 0 & 0 & 0 & 0 & 0\end{array}$

\begin{tabular}{lllllllllllllllllllllllllllllllllllllllllllllll}
0 & 0 & 0 & 0 & 0 & 0 & 0 & 0 & 75 & 0 & 3 & 3 & 3 & 0 & 0 & 0 & 0 & 0 & 0 & 0 & 0 & 0 & 0 & 0 & 0 & 0 & 0 & 0 & 0 & 0 & 0 & 0 & 0 & 0 & 0 & 0 & 0 \\
\hline
\end{tabular}

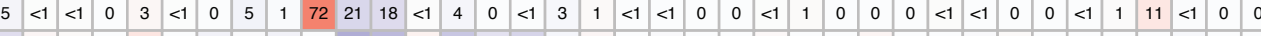

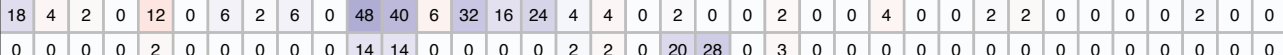

\begin{tabular}{llllllllllllllllllllllllllllllllllllllllllllllll}
11 & 0 & 11 & 0 & 6 & 2 & 2 & 2 & 0 & 0 & 6 & 4 & 9 & 13 & 0 & 0 & 0 & 0 & 2 & 18 & 0 & 0 & 0 & 0 & 0 & 0 & 0 & 11 & 11 & 18 & 0 & 2 & 0 & 2 & 0 & 0 & 4 \\
\hline 11
\end{tabular}

$\begin{array}{lllllllllllllllllllllllllllllllllllllllllllllll}27 & 0 & 0 & 1 & <1 & 1 & 9 & <1 & 0 & 4 & 3 & 1 & 24 & 2 & 0 & 1 & <1 & 6 & <1 & 0 & 0 & 0 & 0 & <1 & 0 & 0 & 0 & 0 & 0 & 2 & 0 & <1 & 13 & 4 & 0 & 0 & 0 \\ & 2 & 0 & 0 & 0 & 1 & 0 & 4 & 4 & 0 & 0 & 7 & 7 & 2 & 0 & 0 & 0 & 2 & 2 & 0 & 2 & 0 & 0 & 0 & 0 & 0 & 0 & 0 & 0 & 0 & 0 & 0 & 0 & 0 & 0 & 0 & 0\end{array}$

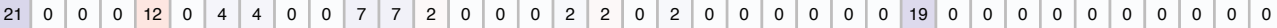

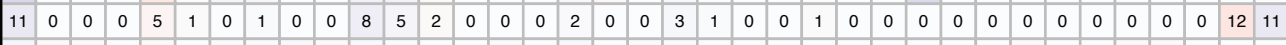

$\begin{array}{llllllllllllll}51 & 67 & 20 & <1 & 4 & 6 & 5 & 3 & 8 & 31 & 42 \\ 52 & 52 & 10 & 0 & 0 & 0 & 7 & 5 & 0 & 7 & 21 & 36 \\ 20 & 10 & & 0 & 0 & 0 & 0 & & 2 & 3 & 1 & 3\end{array}$

$2010 \begin{array}{lllllllllllll}3 & 0 & 0 & 3 & 0 & 3 & 20 & 3 & 13 & 3 \\ 7 & 30 & 3 & 0 & 0 & 0 & 1 & 1 & 1 & 5 & 3 & \end{array}$

\begin{tabular}{lllllllllllll}
30 & 3 & 0 & 0 & 0 & 1 & 1 & 1 & 5 & 3 & 11 \\
\hline & 4 & 0 & 2 & 0 & 0 & 4 & 0 & & 4 & 0
\end{tabular}

\begin{tabular}{llllllllllllll}
6 & 41 & 0 & 2 & 0 & 0 & 4 & 8 & 8 & 4 & 6 \\
\hline & 0 & 0 & 0 & 0 & 0 & 0 & 0 & 6 & 3 & 3 & 75
\end{tabular}

\begin{tabular}{ll|llllllllllll}
3 & 0 & 0 & 0 & 0 & 0 & 0 & 0 & 6 & 3 & 3 & 75 \\
\hline & 7 & 1 & 0 & 0 & 4 & 2 & 2 & 0 & 5 & & 11
\end{tabular}

\begin{tabular}{lllllllllllll}
7 & 11 & 0 & 0 & $<1$ & 2 & 2 & 8 & 5 & 86 & 11 \\
\hline 6 & 26 & 12 & 0 & 2 & 0 & 8 & 6 & 8 & 16 & 48 & 04 \\
14 & 0 & 8 & 0 & 0 & 2 & 0 & 2 & 0 & 0 & 2 & 28 & -1
\end{tabular}

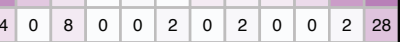

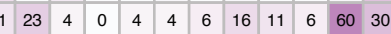

\begin{tabular}{lllllllllllll}
7 & 34 & 16 & 0 & $<1$ & 1 & 3 & 8 & 25 & 13 & 28 & 21 \\
\hline & 21 & 7 & 0 & 2 & 2 & 2 & 4 & 4 & 7 & 4 & 43 & -1
\end{tabular}

\begin{tabular}{llllllll|l|l|l|l|l}
12 & 21 & 7 & 0 & 2 & 2 & 2 & 4 & 4 & 7 & 4 & 43 \\
\hline & 13 & 4 & 0 & 0 & 1 & 2 & 0 & 2 & 6 & 11 & 18
\end{tabular}

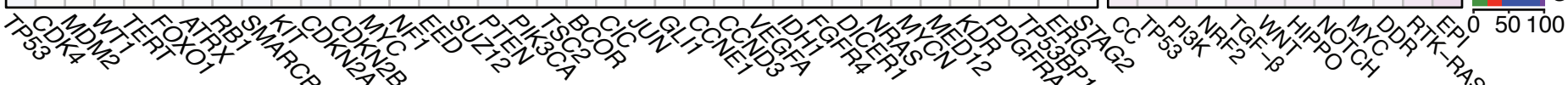

Alteration type $\square$ Mutation $\square$ Amplification $\square$ Deletion $\square$ Fusion

Gene type Oncogene $\square$ Tumor suppressor Both (Pathway)

B

\begin{tabular}{|c|c|c|}
\hline \multirow{3}{*}{ INPP4B } & \multicolumn{2}{|l|}{$\begin{array}{l}\text { PTEN } \\
\text { PTE }\end{array}$} \\
\hline & 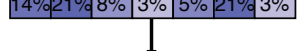 & \begin{tabular}{|l|l|l|l|l|l|l|l|}
$0 \%$ & $1 \%$ & $0 \%$ & $3 \%$ & $5 \%$ & $2 \%$ & $0 \%$ \\
\end{tabular} \\
\hline & PIKЗССА & PIK3R2 \\
\hline 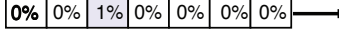 & \begin{tabular}{|l|l|l|l|l|}
$2 \%$ & $2 \%$ & $3 \%$ & $0 \%$ & $5 \%$
\end{tabular} & \begin{tabular}{|l|l|l|l|l|l|l|}
0 & $4 \%$ & $1 \%$ & $0 \%$ & $5 \%$ & $0 \%$ & $0 \%$ \\
\end{tabular} \\
\hline & $\downarrow$ & PIK3R3 \\
\hline & AKT1 & \begin{tabular}{|l|l|l|l|l|l|l|l|}
$0 \%$ & $0 \%$ & $0 \%$ & $0 \%$ & $0 \%$ & $0 \%$ & $0 \%$ \\
\end{tabular} \\
\hline & \begin{tabular}{|l|l|l|l|l|l|l|}
$0 \%$ & $0 \%$ & $1 \%$ & $0 \%$ & $0 \%$ & $2 \%$ & $0 \%$ \\
\end{tabular} & \\
\hline & AKT2 & PP2R1A \\
\hline & \begin{tabular}{|l|l|l|l|l|l|l|}
$2 \%$ & $0 \%$ & $1 \%$ & $5 \%$ & $0 \%$ & $0 \%$ & $0 \%$ \\
\end{tabular} & \begin{tabular}{|l|l|l|l|l|l|l|}
$0 \%$ & $2 \%$ & $0 \%$ & $0 \%$ & $0 \%$ & $0 \%$ & $0 \%$ \\
\end{tabular} \\
\hline & AKT3 & \\
\hline & 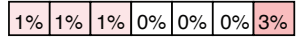 & \\
\hline & TSC1 & \\
\hline STK11 & \begin{tabular}{|l|l|l|l|l|l|l|}
$1 \%$ & $0 \%$ & $1 \%$ & $0 \%$ & $0 \%$ & $2 \%$ & $7 \%$ \\
\end{tabular} & RHEB \\
\hline \begin{tabular}{|l|l|l|l|l|l|}
$3 \%$ & $4 \%$ & $0 \%$ & $0 \%$ & $0 \%$ \\
\end{tabular} & TSC2 & \begin{tabular}{|l|l|l|l|l|l|l|}
$0 \%$ & $0 \%$ & $0 \%$ & $0 \%$ & $5 \%$ & $0 \%$ & $0 \%$ \\
\end{tabular} \\
\hline & \begin{tabular}{|l|l|l|l|l|l|l|}
$0 \%$ & $1 \%$ & $3 \%$ & $0 \%$ & $0 \%$ & $0 \%$ & $30 \%$ \\
\end{tabular} & I \\
\hline & & RPTOR \\
\hline RICTOR & & \begin{tabular}{|l|l|l|l|l|l|l|l|}
$0 \%$ & $0 \%$ & $0 \%$ & $0 \%$ & $0 \%$ & $0 \%$ & $0 \%$ \\
\end{tabular} \\
\hline \begin{tabular}{|c|c|c|c|c|c|c|}
$1 \%$ & $1 \%$ & $1 \%$ & $5 \%$ & $0 \%$ & $0 \%$ & $0 \%$ \\
mTORC2
\end{tabular} & Cell growth & 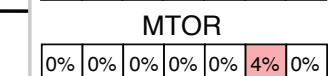 \\
\hline
\end{tabular}

mTORC1
C Oncogenic TERT alterations

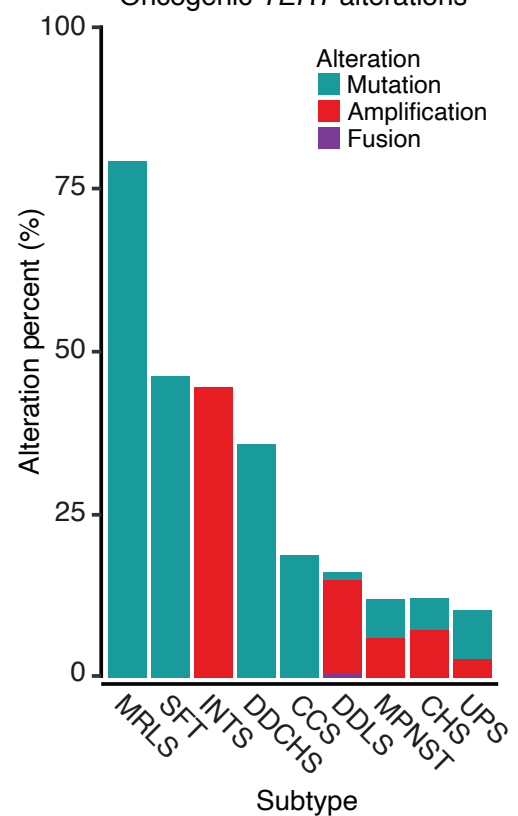

D

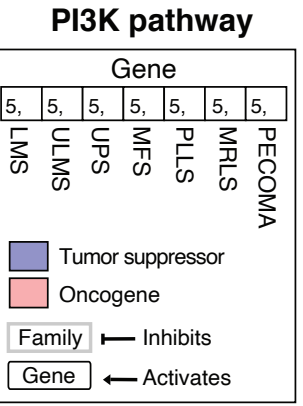

Arginine methylation

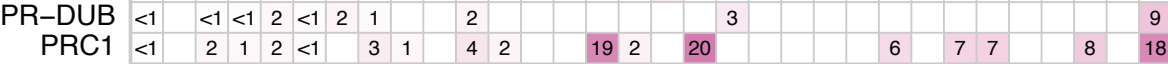

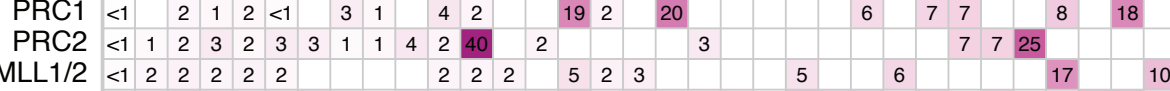

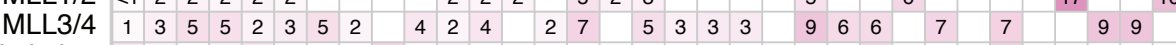

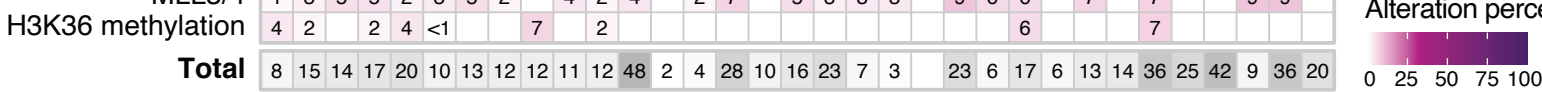

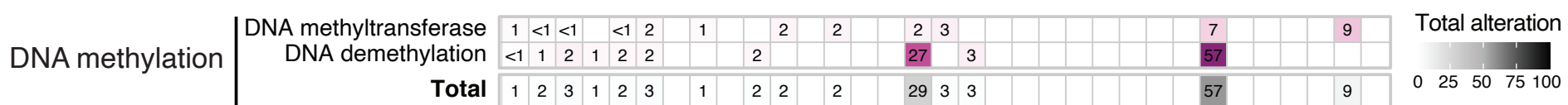

Chromatin remodeling

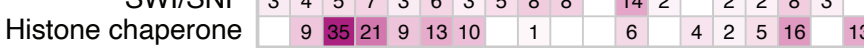

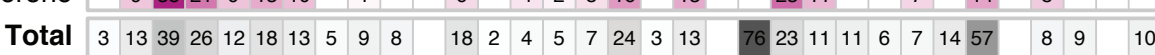

Figure 4. Integrated pathway analysis. A, Oncogenic alterations within each of 12 pathways with relevance to cancer biology in each subtype. Numbers in each cell indicate percentage of samples harboring alterations. Stacked bar graphs indicate the distribution of the type of oncogenic alteration per gene or pathway (top) or subtype (right). CC, cell cycle; EPI, epigenetic. B, PI3K pathway alterations in specific subtypes. The percentage of samples with an alteration in a specific gene in each subtype is indicated in each box. C. Oncogenic TERT promoter alterations in each of the 9 most altered subtypes. D, Oncogenic epigenetic pathway alterations by subtype, grouped by complex and/or biochemical function of the encoded protein. Totals include all alterations in genes that belong to a parent category, not only those affecting specific complexes listed. 
A
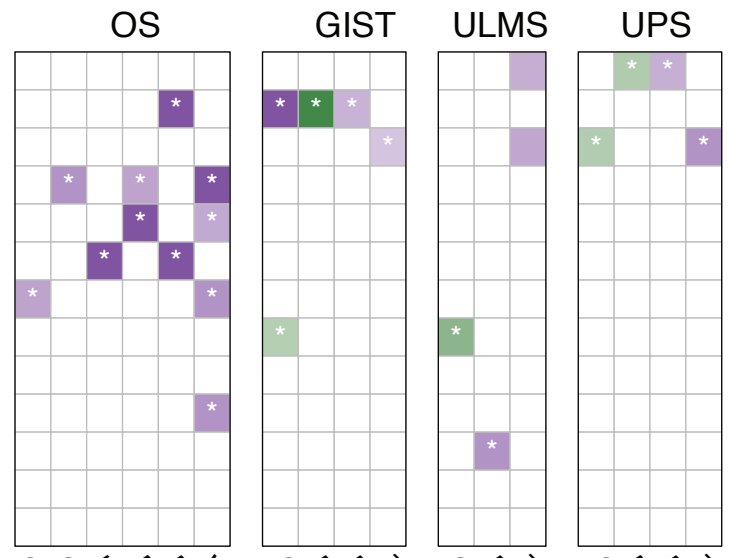

ANGS DDLS ES SFT

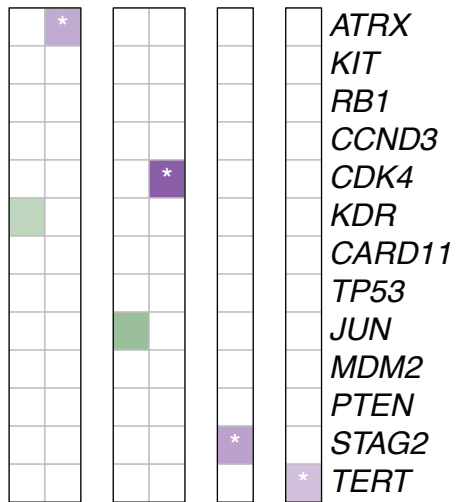

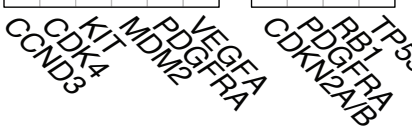
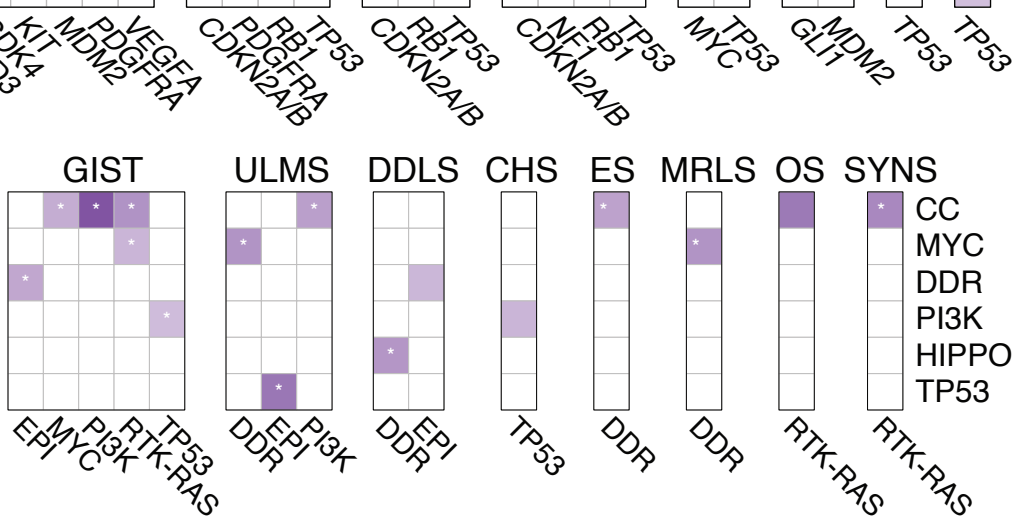

Mutual exclusivity

-log(p-val)

$$
\begin{array}{llll}
0 & 2 & 4 & 6
\end{array}
$$

Co-occurrence

$-\log (p-v a l) \quad *$ FDR $<0.05$
B

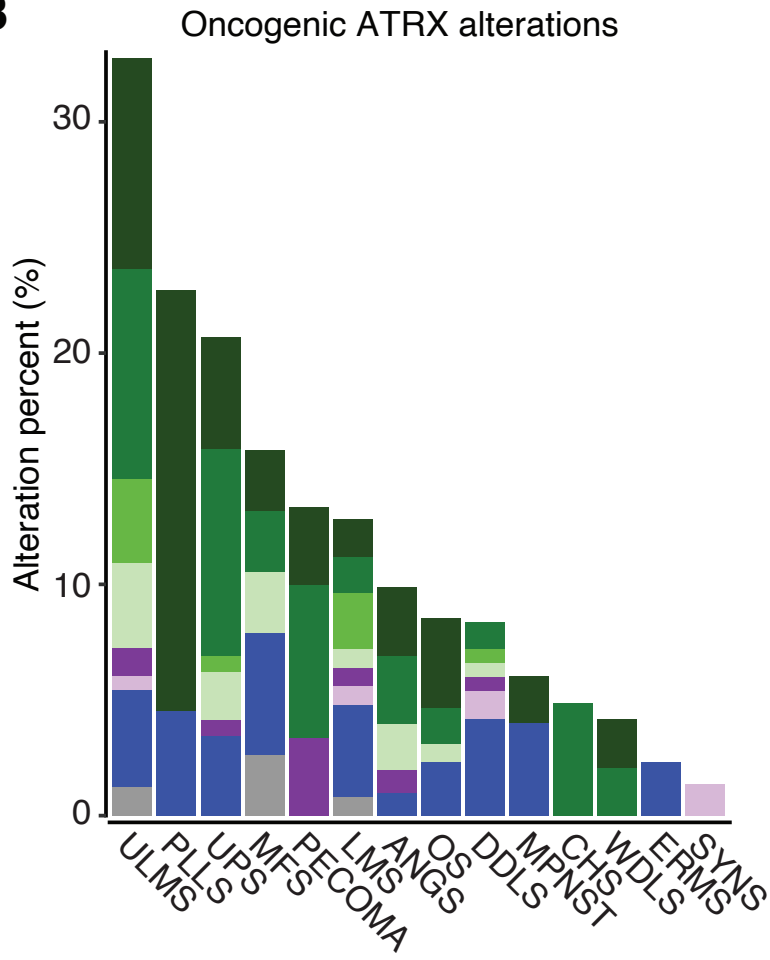

Alteration type

Nonsense mutation

Frame shift deletion

Frame shift insertion

Splice site mutation

Intragenic fusion

Fusion

Deletion

Multiple variants
C

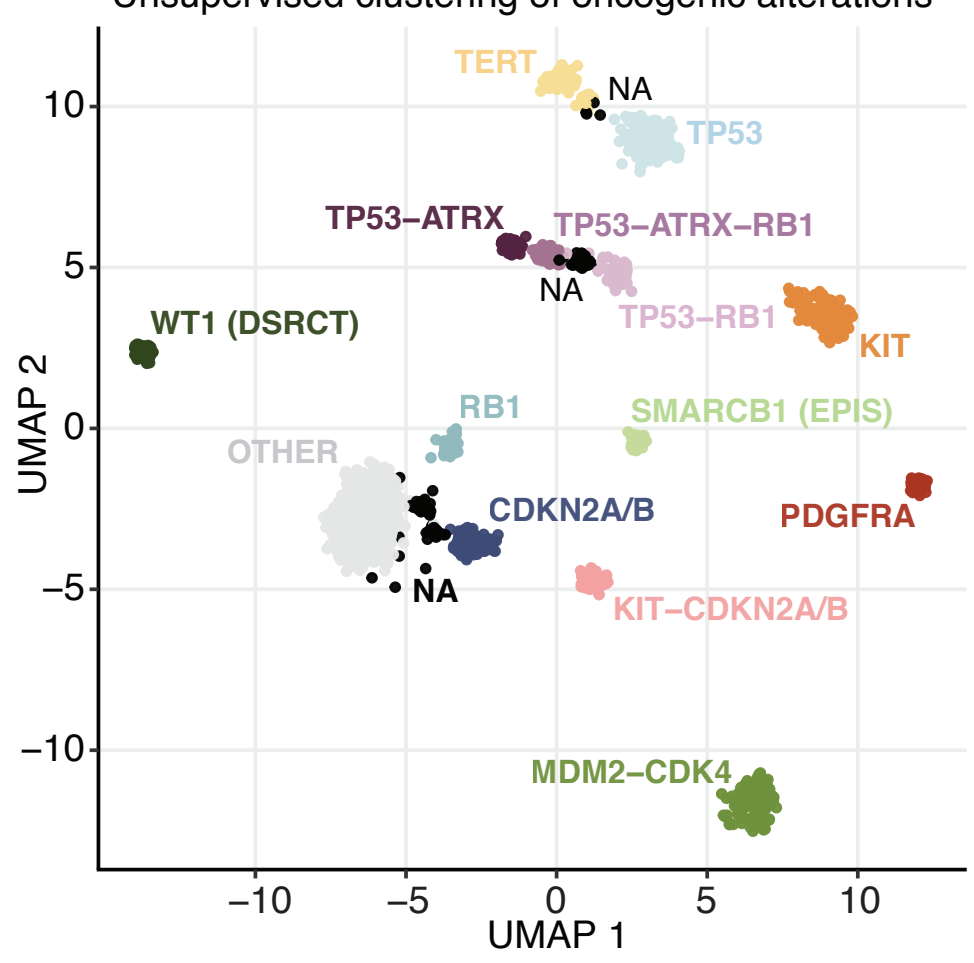

D

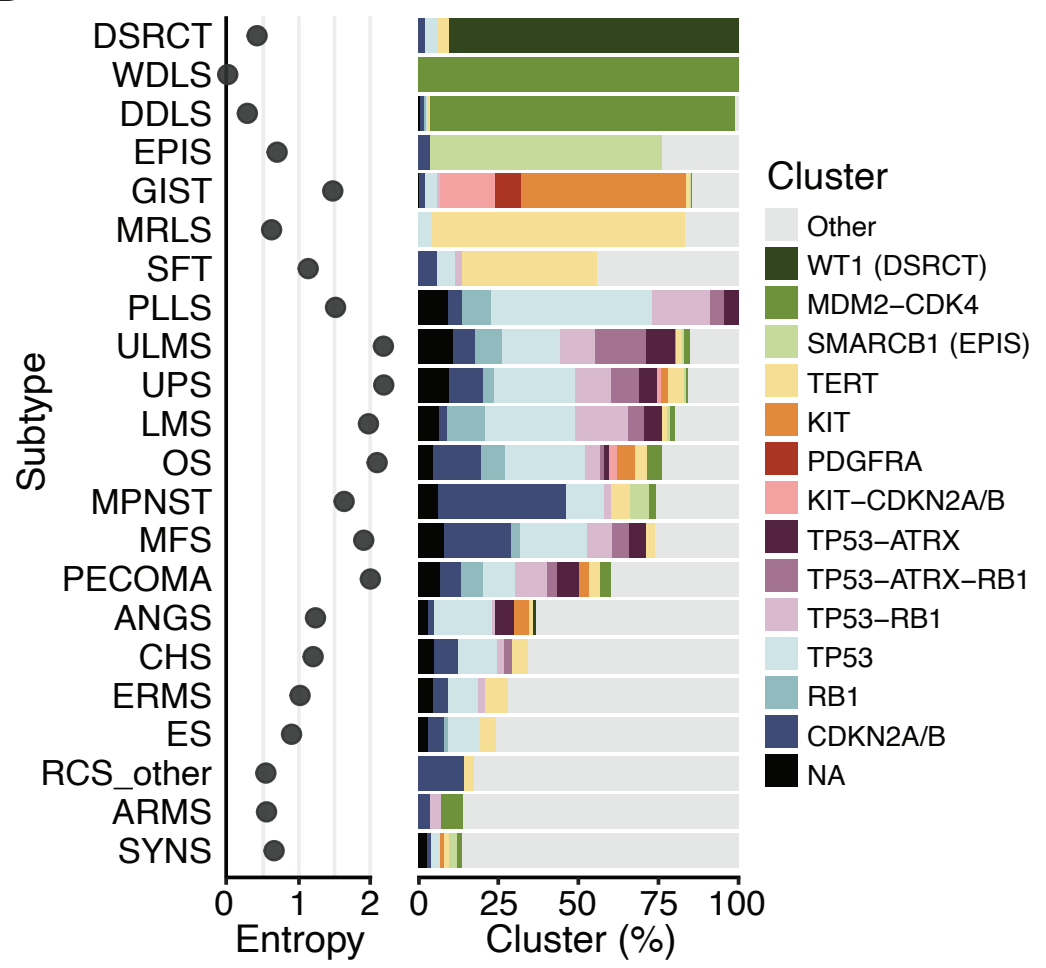

Figure 5. Mutual exclusivity, co-occurrence, ATRX alterations, and unsupervised clustering based on genetic signatures. A, Co-occurrence and mutual exclusivity of gene- (top) and pathway-level (bottom) alterations in each subtype. B, Frequency and types of oncogenic ATRX alterations in each of the 14 most altered subtypes. C. Unsupervised clustering of samples based on oncogenic alteration patterns. D, Subtype-specific cluster associations and entropy scores. 
A medRxiv preprint doi: https://doi.org/10.1101/2021.10.28.21265587; this version pgsted October 30, 2021. The copyright holder for this preprint
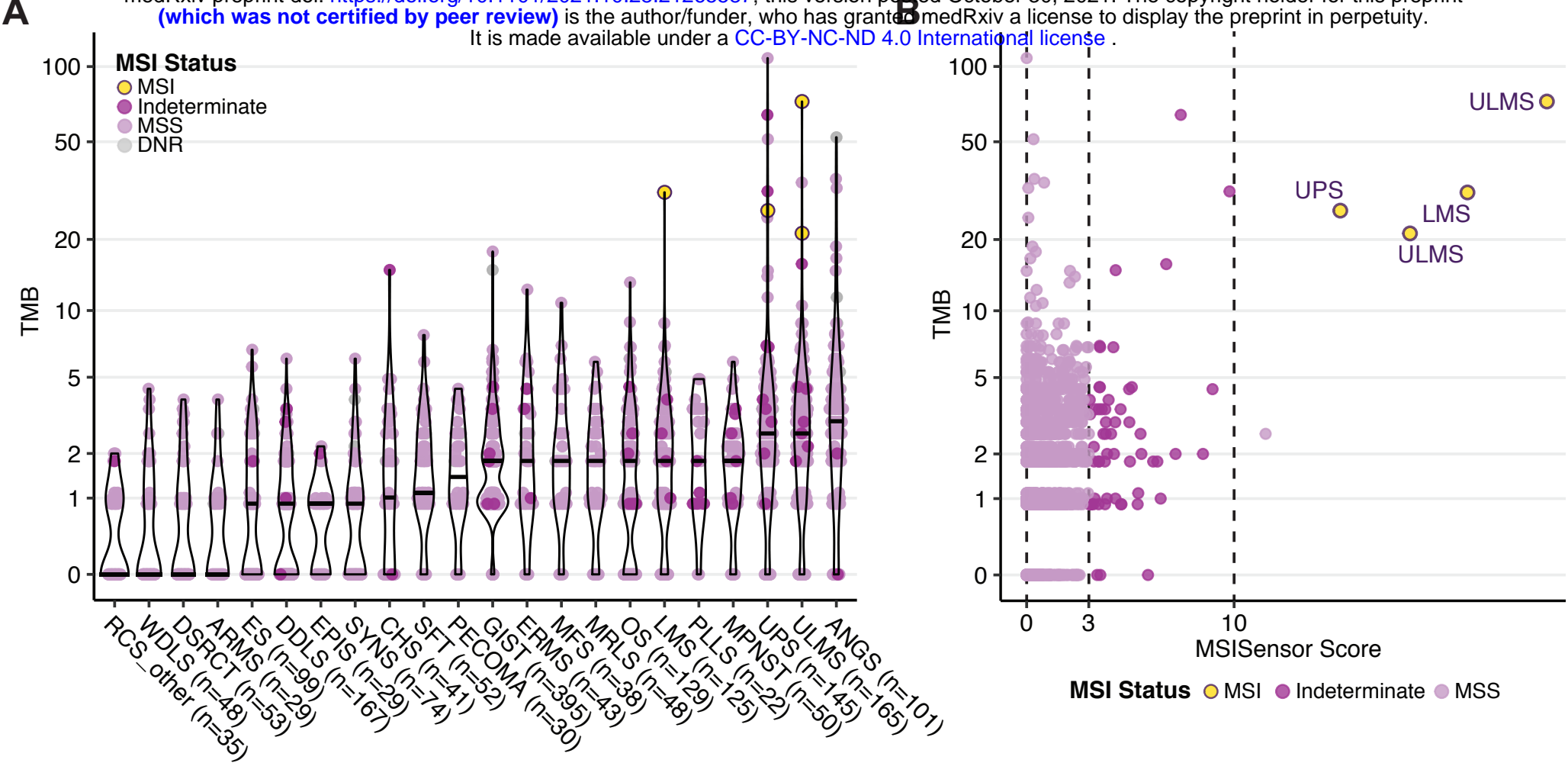

C
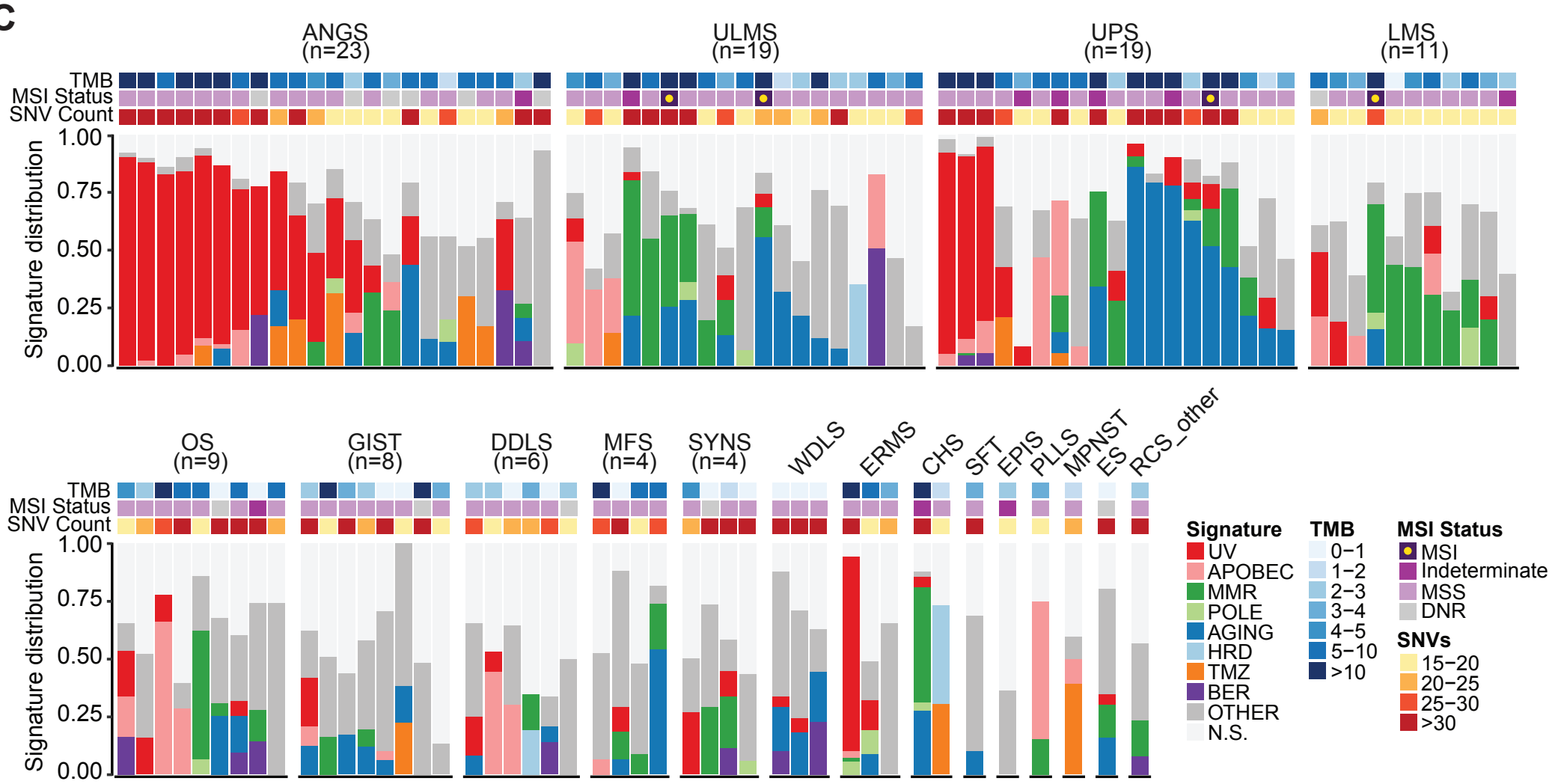

Figure 6. Tumor mutation burden (TMB), microsatellite instability (MSI) status, and mutational signatures. A, Distribution of TMB (mutations/Mb) by subtype with sample-level MSI status. B, MSISensor score versus TMB for the cohort with sample-level MSI status. C, Mutational signature profile of each evaluable sample. Each bar represents the signature distribution of an individual sample, grouped by subtype. TMB, MSI status, and single nucleotide polymorphism (SNV) count are shown above. 
B
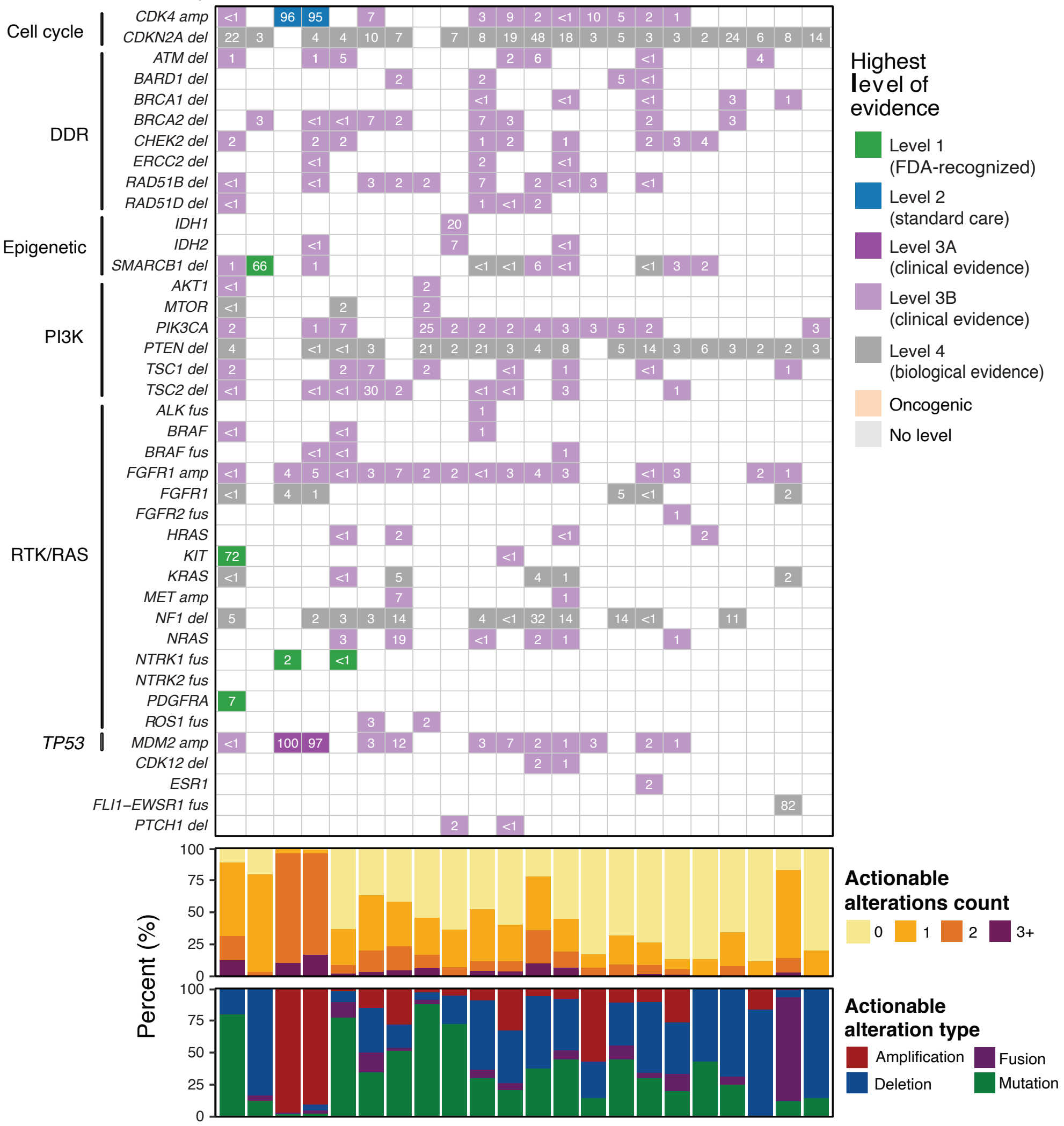

Highest

level of

evidence

Level 1

(FDA-recognized)

Level 2

(standard care)

Level 3A

(clinical evidence)

Level 3B

(clinical evidence)

Level 4

(biological evidence)

Oncogenic

No level

(which reprint doi: https this preprint

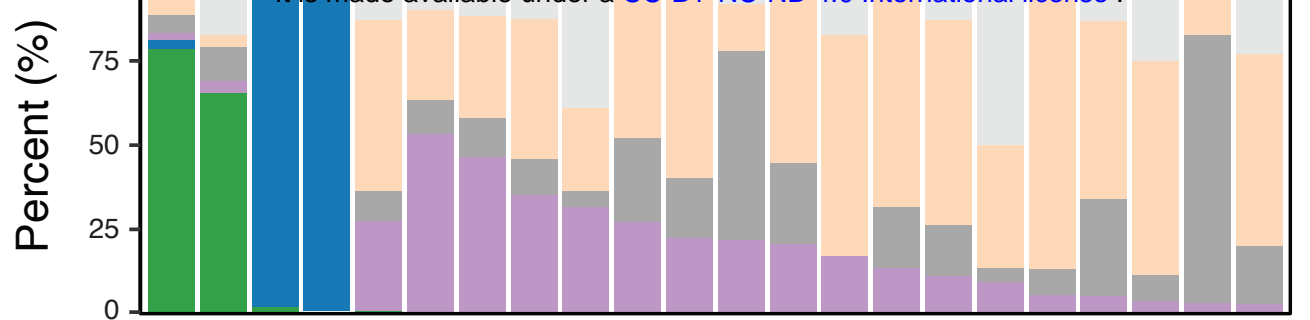

(which was not certified by peer review) is the author/funder tho has aranted medRxiv a license to display the preprint in perpetuity. 
A
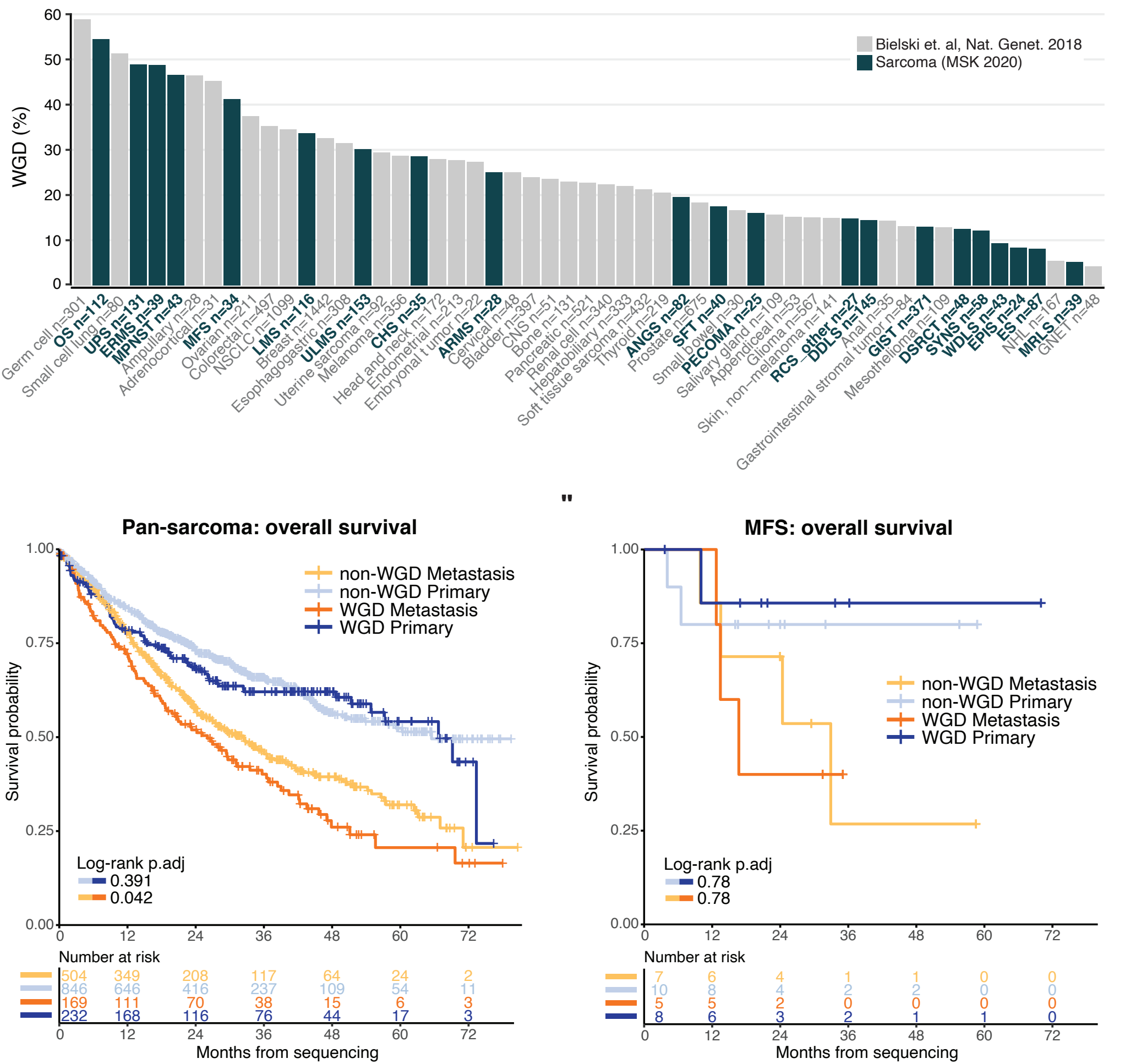

Supplementary Figure 1. Whole genome doubling (WGD) and survival probability. A, Frequency of WGD by subtype (green) compared to other cancers (all available samples) (gray). B-C, Overall survival based on WGD status within metastatic and primary tumor cohorts in B, all sarcoma subtypes; C, MFS. 


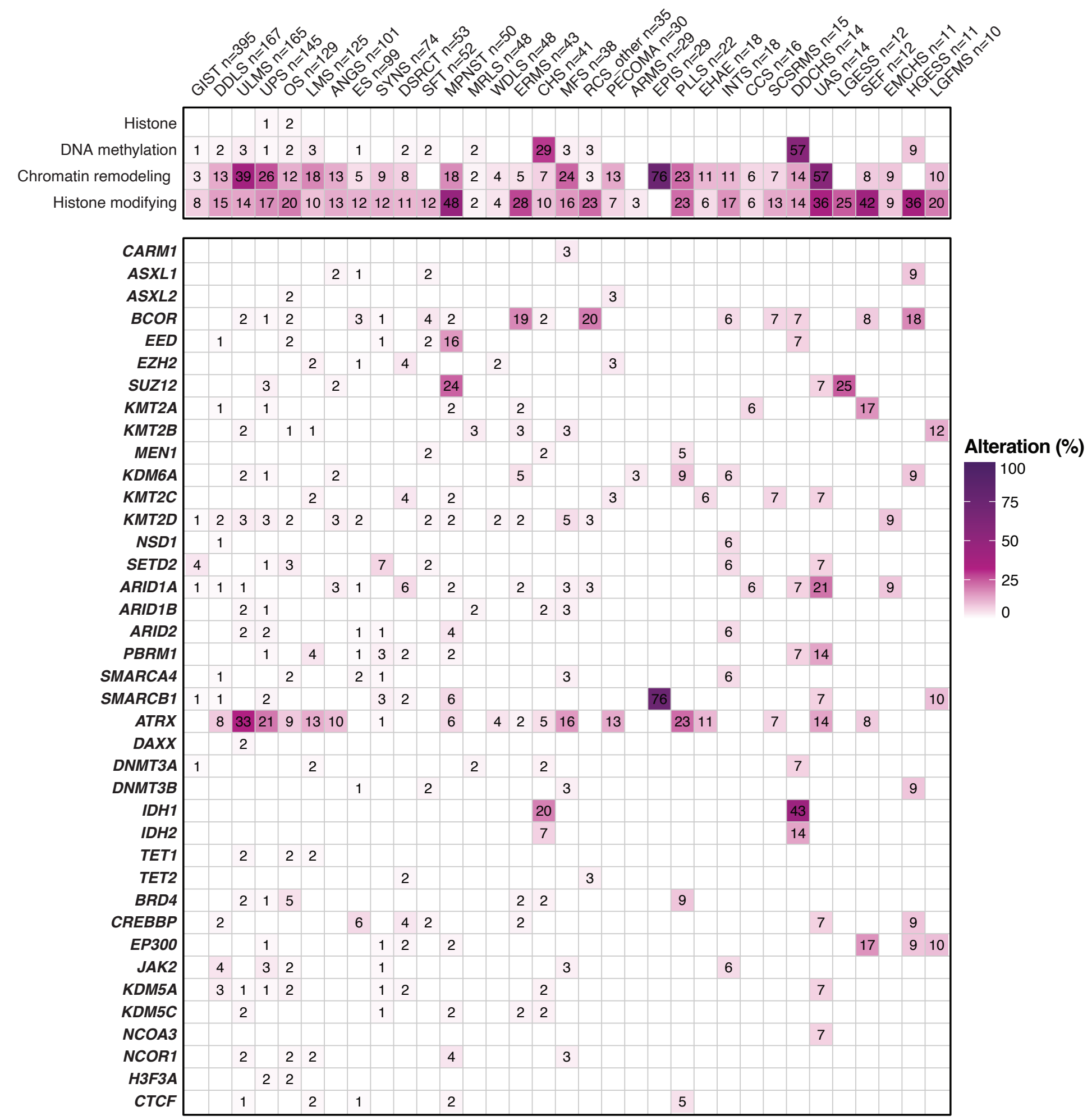

Supplementary Figure 2. Oncogenic epigenetic pathway alterations. Frequency of oncogenic alterations in specific epigenetic pathway genes in each subtype with $\geq 10$ samples. Top box, aggregate number of alterations in each gene family/biochemical process. 
medRxiv preprint doi: https:I/dôi.org $10,110172021.10 .28 .21265587$; this version posted October 30,2021. The copyright holder for this prep (wlifishowas Bot certified by peer geview) is thezauthor/fanderz who has granted medRxiv fa license to display the preprint in perpetuity.

DNA methylation Chromatin remodeling

Histone modifying

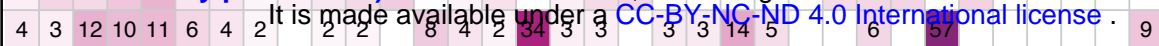

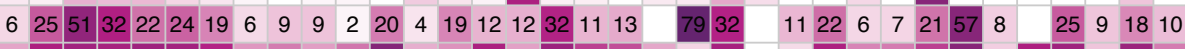

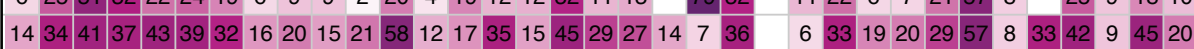

\begin{tabular}{|c|c|c|c|c|c|c|c|c|c|c|c|c|c|c|c|c|c|c|c|c|c|c|c|c|c|c|c|c|}
\hline Arginine methylation & $<1$ & 3 & 5 & 3 & 3 & & & & & & & & & 5 & 3 & & & & 13 & & & & & & & & & \\
\hline PR-DUB & $<1$ & & 2 & 4 & 2 & 2 & 32 & & 2 & 2 & 2 & & & & & se & 3 & & & & & & & & & & & 9 \\
\hline PRC1 & $<1$ & & 6 & 3 & 2 & 3 & 2 & 41 & & 4 & 4 & & 21 & 192 & & 20 & & & & & 6 & & 7 & 7 & & 8 & 1 & 18 \\
\hline PRC2 & $<1$ & 3 & 2 & 6 & 2 & 3 & 4 & 1 & 4 & 2 & 40 & & 2 & & 3 & ( & 3 & & & & & & 7 & 77 & & & & \\
\hline MLL1/2 & 3 & 3 & 5 & 5 & 4 & 6 & 4 & 4 & & 4 & 4 & 6 & & 75 & 8 & & & & 5 & & & 6 & & 7 & & 17 & & 910 \\
\hline MLL3/4 & 3 & 5 & 8 & 9 & 5 & 6 & 133 & 31 & 4 & 4 & 10 & 2 & 47 & 7 & 16 & 31 & 103 & & 9 & & 617 & & 7 & & 48 & & 91 & 18 \\
\hline H3K36 methylation & 5 & 5 & 4 & 8 & 9 & 2 & 4 & 8 & & 6 & 2 & & 22 & 2 & 5 & & 3 & & 5 & & 6 & & 7 & 14 & & & & \\
\hline SWI/SNF & 5 & 18 & 12 & 111 & & 9 & 116 & 8 & 8 & 2 & 14 & 4 & 129 & 97 & 16 & 3 & & & 14 & & 22 & 6 & & $14<$ & 38 & 17 & 91 & 1810 \\
\hline Histone chaperone & 1 & 10 & $41:$ & 23 & & 18 & 111 & 1 & 2 & & 8 & & 62 & 25 & 16 & & 13 & & 323 & 11 & & & 7 & 714 & & 8 & & \\
\hline NA methyltransferase & 2 & 2 & 6 & 5 & 7 & 4 & $<12$ & & & 2 & & 6 & 2 & 10 & 03 & & 3 & 3 & 9 & & & 6 & & 7 & & & (se & 9 \\
\hline DNA demethylation & 2 & 1 & 6 & 8 & 4 & 2 & 4 & & 2 & & & 2 & 22 & & & 3 & & & $\begin{array}{ll}35 \\
\end{array}$ & 5 & & & & & & & & \\
\hline
\end{tabular}

\begin{tabular}{|c|c|c|c|c|c|c|c|c|c|c|c|c|c|c|c|c|c|c|c|c|c|c|c|c|c|c|c|c|c|c|}
\hline CARM1 & $<1$ & 3 & 5 & 3 & 3 & & & & & & & & & & \begin{tabular}{|l|l|}
5 & 3 \\
\end{tabular} & & & & 13 & & & & & & & & & & & \\
\hline$A S X L 1$ & $<1$ & & 2 & 2 & $<$ & $=13$ & 3 & 2 & & 2 & 2 & & & & & & & & & & & & & & & & & & 9 & \\
\hline$A S X L 2$ & & & & 3 & $2<$ & $<1$ & & & 2 & ? & & & & & & & 3 & & & & & & & & & & & & & \\
\hline$B C O R$ & $<1$ & & 6 & 3 & 23 & 3 & . & 4 & 1 & 4 & 4 & & 2 & 192 & & 20 & 3 & & & & & 6 & 7 & 7 & & & 8 & & 18 & \\
\hline EED & & 2. & $<1$ & $<1$ & $2<$ & $<1$ & & 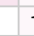 & 1 & & 216 & & & & & & & & & & & & 7 & 7 & & & & & & \\
\hline$E Z H 1$ & & & & 1 & & & & & & & & & & & & & & & & & & & & & & & & & & \\
\hline$E Z H 2$ & & $<1$ & 1 & 2 & 2 & $2<<r y$ & $=1$ & 1 & 4 & 4 & & & 2 & & 3 & & 3 & & & & & & & & & & 8 & & & \\
\hline SUZ12 & $<1$ & & $<1$ & 3 & & & 3 & & & & 24 & & & & & & & & & & & & & & 7 & & 25 & & & \\
\hline KMT2A & 1 & 2 & 3 & 3 & 22 & 2 & 2 & 1 & 1 & 2 & 2 & 4 & & 22 & \begin{tabular}{|l|l|}
2 & 3
\end{tabular} & & & & 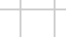 & & & 6 & & 7 & & & 17 & & & \\
\hline KMT2B & 2 & $<1$ & 3 & 2 & 15 & 5 & 3 & 6 & & & 3 & 3 & & 6 & 7 & & & & & & & & & & 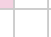 & & & & 12 & \\
\hline MEN1 & $<1$ & $<1$ & $<1$ & 1 & $<1<$ & $=1$ & & & & 2 & & & & & 2 & & & & 5 & & & & & & & & & & 9 & \\
\hline KDM6A & $<1$ & & 3 & 2 & & 3 & 3 & & & & 2 & & 2 & 5 & & & 3 & 3 & 9 & & & 116 & & & 7 & & & & 9 & \\
\hline KMT2C & 1 & 1 & 1 & 2 & 23 & 3 & 3 & 1 & 14 & & 6 & & & & 3 & & 3 & & & & 6 & & 7 & & 7 & & & & & \\
\hline KMT2D & 2 & 4 & 4 & 6 & 22 & 2 & 7 & & & 4 & 44 & 2 & 4 & 2 & 16 & 3 & 3 & & & & & 116 & & & & 8 & & 9 & 9 & \\
\hline NSD1 & $<1$ & 2 & 2 & 3 & $4<$ & $=1$ & 2 & & & 4 & & & & 2 & & & & 3 & & & & 6 & 7 & & & & & & & Alteration (\%) \\
\hline NSD2 & $<1$ & 3 & 2 & 1 & 1 & 1 & 3 & 3 & 3 & & & & 3 & & 3 & & & & & & & & & & & & & & & ) \\
\hline SETD2 & 4 & 1 & 1 & 5 & 5 & & & 7 & 7 & 2 & 22 & & & & 3 & & & & 5 & & & 6 & & & 14 & & & & & \\
\hline ARID1A & 2 & 2 & 2 & 2 & & 2 & 4 & 1 & $\epsilon$ & 6 & 2 & & & 2 & 5 & 3 & & & & & & 6 & & & 21 & & & 9 & & \\
\hline$A R I D 1 B$ & 1 & 7 & 2 & 1 & 32 & 2 & 2 & 1 & & & & 2 & 4 & 2 & 25 & & & & & & & & & & & & & & & 75 \\
\hline ARID2 & 1 & 3 & 4 & 2 & $<1$ & & $=1$ c1 & 11 & & 2 & 24 & & 6 & & & & & & 3 & & 1 & 11 & & & & 8 & & & & \\
\hline PBRM1 & $\mid<1$ & 1. & $<1$ & 3 & $<1<1$ & 4 & 2 & 13 & 3 & & 2 & & & 2 & 2 & & & & & & & & & & 14 & & 17 & & 9 & 50 \\
\hline SMARCA4 & & 4 & 4 & 1 & 62 & 2 & 2 & 21 & 1 & & & & 2 & & 25 & & & & 14 & & & 6 & & & & & & & & \\
\hline SMARCB1 & 1 & 1. & $<1$ & 3 & 22 & $2<$ & $<1$ & 3 & 3 & & 6 & 2 & & 2 & & & & & 76 & & & & & & 7 & & & & 910 & 25 \\
\hline SMARCD1 & & 2 & $<1$ & & & & $<1$ & & & & & & 2 & & & & & & & & & 17 & & & & & & & & \\
\hline ATRX & $<1$ & 9 & $37:$ & 23 & 91 & 171 & 10 & 11 & 1 & & 8 & & 6 & 2 & 516 & 3 & 13 & & 323 & & 11 & & 7 & 7 & 14 & & 8 & & & 0 \\
\hline$D A X X$ & $<1$ & 1 & 4 & & $<1<$ & $=1<<$ & $=1$ & & 2 & 2 & & & & & & 6 & & & & & & & & & & & & & & \\
\hline DNMT1 & $<1$ & 1 & 4 & 3 & 5 & 2 & s. & 1 & & & & & 2 & & 7 & & & & 9 & & & 6 & & & & & & & & \\
\hline DNMT3A & 1 & $<1$ & 2 & 2 & 22 & $2<<$ & $=1$ & & & & & 6 & & & 2 & & & & & & & & & 7 & & & & & & \\
\hline DNMT3B & $<1$ & & & $<1$ & & & . & 1 & & 2 & 2 & & & & 3 & & & 3 & & & & & & & & & & & 9 & \\
\hline IDH1 & & & 1 & $<1$ & $<$ & $\leqslant 1$ & & & & & & & 2 & & 20 & & & & & & & & & 45 & & & & & & \\
\hline IDH2 & $<1$ & $<1$ & 2 & 2 & $<1$ & r & 2 & & & & & 2 & & & 7 & & & & 5 & & & & & 14 & & & & & & \\
\hline TET1 & & & 3 & 4 & 22 & 2 & 2 & & & & & & & 2 & & & & & & & & & & & & & & & & \\
\hline TET2 & $<1$ & & 1 & 1 & 2 & & & & 2 & & & & & & & 3 & & & 3 & 5 & & & & & & & & & & \\
\hline BRD4 & $<1$ & $<1$ & 4 & 2 & $5<$ & $k 1<$ & $<1$ & & 2 & ? & 2 & & & 2 & 2 & & & & 9 & & & & & & & & & & & \\
\hline CREBBP & 1 & 2 & 1 & 2 & 24 & 4 & 3 & 6 & 4 & 42 & 2 & & & 2 & & & & & 3 & & & & & & 7 & & & & 9 & \\
\hline DOT1L & $<1$ & 1 & 4 & 2 & 32 & 2 & 2 & & & & 2 & & & & 2 & & & 3 & & & & 66 & & & & & & & & \\
\hline EP300 & $<1$ & 2 & 2 & 2 & 2 & & 2 & 1 & 12 & 22 & 2 & & & & & & & & 5 & & & 6 & & & & & 17 & & 910 & \\
\hline JAK2 & $<1$ & 5 & 4 & 4 & 2 & $2<$ & $=1$ & 1 & 12 & 2 & 4 & & & & 3 & & & & & & & 6 & & & & & & & & \\
\hline KDM5A & $<1$ & 4 & 4 & 1 & $4<$ & $<1<<<$ & $<1$ & 1 & 1 & & & & 2 & & 23 & 3 & 3 & & & & & & & & 7 & & & & & \\
\hline KDM5C & $<1$ & & 4 & 2 & 22 & 2 & 2 & 1 & 1 & & 2 & & 2 & 2 & 2 & & & & & & & 6 & & & 7 & & & & 9 & \\
\hline KMT5A & & $<1$ & & & & & & & & & & 3 & 3 & & & & & & & & & & & & & & & & & \\
\hline NCOA3 & & 2 & $<1$ & $<1$ & & & . & 12 & 2 & 2 & 2 & & 2 & & 3 & & & 4 & & & & & & & 7 & & & & 11 & \\
\hline NCOR1 & & $<1$ & 10 & 6 & 211 & 192 & 2 & & & & 6 & 2 & & 2 & 28 & 3 & & & 3 & & & 6 & & 7 & & & & & & \\
\hline NSD3 & & 5 & 1 & 3 & 7 & 1 & & 3 & 3 & 4 & 43 & & & 3 & 5 & & 6 & & & & & & & & & & & & & \\
\hline SMYD3 & & & 1 & & & & 3 & 2 & & & 3 & 3 & & 3 & 3 & & 6 & & & & & & & & & & & & & \\
\hline H3F3A & $<1$ & & $<1$ & 2 & 2 & & . & 1 & & & & & & & & & 4 & & & & & & & & 7 & & & & & \\
\hline H3F3B & $<1$ & & & & & & & & & & 2 & & 2 & & & & . & & & & & 77 & & & & & & & & \\
\hline H3F3C & & 1 & & 2 & $2<$ & $<1$ & & & & 2 & 2 & & & & & 3 & 3 & & & & & & & & & & & & & \\
\hline HIST1H1C & & & 1. & $<1$ & $2<$ & $\leqslant 1<$ & $<1$ & 1 & 1 & & & & & & & 3 & 3 & & & & & & & & & & & & & \\
\hline HIST1H2BD & & & 2 & & 22 & 2 & & & & & & & & & & 3 & 3 & & & & & & & & & & & & & \\
\hline HIST1H3A & $<1$ & & $2<$ & $<1$ & $2<$ & $<1$ & & & & & & & & & & 3 & 4 & & & & & & & & & & & & & \\
\hline HIST1H3B & $<1$ & $<1$ & $2<$ & $<1$ & $2<$ & $<1$ & & & & & & & & & & 3 & 3 & & & & & & & & & & & & & \\
\hline HIST1H $3 C$ & $<1$ & & $2<$ & $<1$ & $2<$ & & & & 2 & & 2 & & & & & 3 & 4 & & & & & & & & & & & & & \\
\hline HIST1H3D & $<1$ & & 3 & & $2<$ & $=1$ & 1 & & & & & & & 2 & & 3 & 4 & & & & & & & & & & & & & \\
\hline HIST1H3E & $<1$ & & 3 & $<1$ & 22 & 2 & & & & & 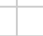 & & & 2 & & 3 & 4 & & & & & & & & & & & & & \\
\hline HIST1H3F & $<1$ & & 2 & & $2<$ & $=1$ & & & 2 & 2 & & & & 5 & & 3 & 4 & & & & & & & & & & & & & \\
\hline HIST1H3G & $<1$ & & 2 & $<1$ & 32 & 2 & & & & & & & & 2 & & 3 & 4 & & & & & & & & & & & & & \\
\hline HIST1H3H & $<1$ & & 2 & 2 & 2 & & 1 & 1 & 2 & 2 & & & & 2 & & 3 & 4 & & & & & & & & & & & & & \\
\hline HIST1H3I & $<1$ & & 2 & & 3 & & & & & & & & & 2 & & 3 & 4 & & & & & & & & & & & & & \\
\hline HIST1H3J & $<1$ & & 2 & & 2 & & & & & 2 & 2 & & & & & 3 & 4 & & & & & & & & & & & & & \\
\hline HIST2H3C & $<1$ & 4 & 3 & $<1$ & 6 & & s. & 1 & & 2 & 25 & & & 2 & & & & & & & & & 8 & & & & & & & \\
\hline HIST2H3D & $<1$ & 4 & 2 & $<1$ & 5 & & . & 1 & & 2 & 25 & & & 2 & & & & & & & & & 8 & & & & & & & \\
\hline HIST3H3 & & $<1$ & $<1$ & $<1$ & & & 1 & 1 & & & & & & & 3 & & 4 & & & & & & & & 7 & & & & & \\
\hline CTCF & $<1$ & & 1 & 1 & & $2<$ & $<1$ & 1 & & & 2 & & & 2 & & & & & 5 & & & & & & 7 & & & & & \\
\hline
\end{tabular}

Supplementary Figure 3. All epigenetic pathway alterations, including variants of unknown significance (VUS). Frequency of somatic alterations in epigenetic pathway genes in each subtype with $\geq 10$ samples. Top boxes, aggregate number of alterations in each gene family and biochemical process. 